\title{
Unraveling the Molecular Players at the Cholinergic Efferent Synapse of the Zebrafish Lateral Line
}

\author{
${ }^{\circ}$ Agustín E. Carpaneto Freixas, ${ }^{1}{ }^{\circ}$ Marcelo J. Moglie, ${ }^{1}$ Tais Castagnola, ${ }^{1}$ Lucia Salatino, ${ }^{2}$ Sabina Domene, ${ }^{3}$ \\ Irina Marcovich, ${ }^{1}$ Sofia Gallino, ${ }^{1}$ Carolina Wedemeyer, ${ }^{1}$ Juan D. Goutman, ${ }^{1}$ Paola V. Plazas, ${ }^{2 *}$ and \\ (1)Ana Belén Elgoyhen ${ }^{1 *}$ \\ ${ }^{1}$ Instituto de Investigaciones en Ingeniería Genética y Biología Molecular, Consejo Nacional de Investigaciones Científicas y Técnicas, 1428 Buenos \\ Aires, Argentina, ${ }^{2}$ Instituto de Farmacología, Facultad de Medicina, Universidad de Buenos Aires, 1121 Buenos Aires, Argentina, and ${ }^{3}$ Centro de \\ Investigaciones Endocrinológicas "Dr. César Bergadá" (CEDIE), Consejo Nacional de Investigaciones Científicas y Técnicas-Fundación de \\ Endocrinología Infantil FEI, División de Endocrinología, Hospital de Niños "Ricardo Gutiérrez" 1425 Buenos Aires, Argentina
}

The lateral line (LL) is a sensory system that allows fish and amphibians to detect water currents. LL responsiveness is modulated by efferent neurons that aid in distinguishing between external and self-generated stimuli, maintaining sensitivity to relevant cues. One component of the efferent system is cholinergic, the activation of which inhibits afferent activity. LL hair cells (HCs) share structural, functional, and molecular similarities with those of the cochlea, making them a popular model for studying human hearing and balance disorders. Because of these commonalities, one could propose that the receptor at the LL efferent synapse is a $\alpha 9 \alpha 10$ nicotinic acetylcholine receptor (nAChR). However, the identities of the molecular players underlying ACh-mediated inhibition in the LL remain unknown. Surprisingly, through the analysis of single-cell expression studies and in situ hybridization, we describe that $\alpha 9$, but not the $\alpha 10$, subunits are enriched in zebrafish HCs. Moreover, the heterologous expression of zebrafish $\alpha 9$ subunits indicates that homomeric receptors are functional and exhibit robust AChgated currents blocked by $\alpha$-bungarotoxin and strychnine. In addition, in vivo $\mathrm{Ca}^{2+}$ imaging on mechanically stimulated zebrafish LL HCs show that ACh elicits a decrease in evoked $\mathrm{Ca}^{2+}$ signals, regardless of HC polarity. This effect is blocked by both $\alpha$-bungarotoxin and apamin, indicating coupling of ACh-mediated effects to small-conductance $\mathrm{Ca}^{2+}$-activated potassium (SKs) channels. Our results indicate that an $\alpha 9$-containing $(\alpha 9 *)$ nAChR operates at the zebrafish LL efferent synapse. Moreover, the activation of $\alpha 9 *$ nAChRs most likely leads to LL HC hyperpolarization served by SK channels.

Key words: calcium imaging; efferent; lateral line; nicotinic receptor; Xenopus oocytes; zebrafish

\section{Significance Statement}

The fish lateral line (LL) mechanosensory system shares structural, functional, and molecular similarities with those of the mammalian cochlea. Thus, it has become an accessible model for studying human hearing and balance disorders. However, the molecular players serving efferent control of LL hair cell (HC) activity have not been identified. Here we demonstrate that, different from the hearing organ of vertebrate species, a nicotinic acetylcholine receptor composed only of $\alpha 9$ subunits operates at the LL efferent synapse. Activation of $\alpha 9$-containing receptors leads to LL HC hyperpolarization because of the opening of small-conductance $\mathrm{Ca}^{2+}$-activated potassium channels. These results will further aid in the interpretation of data obtained from LL HCs as a model for cochlear HCs.

Received July 9, 2020; revised Sep. 25, 2020; accepted Oct. 30, 2020.

Author contributions: A.E.C.F., M.J.M., P.V.P., and A.B.E. designed research; A.E.C.F., M.J.M., T.C., L.S., C.W., and P.V.P. performed research; S.D., I.M., S.G., and J.D.G. contributed unpublished reagents/analytic tools; A.E.C.F. and P.V.P. analyzed data; A.E.C.F., P.V.P., and A.B.E. wrote the paper.

*P.V.P. and A.B.E. contributed equally to this work.

This research was supported by Agencia Nacional de Promoción Científica y Técnica (Argentina Grant PICT 2016-2537 to A.B.E. and Grant PICT 2013-1117 to P.V.P.), Consejo Nacional de Investigaciones Científicas y Técnicas (Argentina; Grant PIP 2014-301 to P.V.P.), Human Frontiers in Science Program (Grant RGP0033/2014 to Hernán Lopez-Schier, Florian Engert, and A.B.E.), and Scientific Grand Prize from the Fondation Pour L'Audition to A.B.E. We thank Hernán Lopez Schier and Florian Engert for academic discussions.

I. Marcovich's present address: Departments of Otolaryngology and Neurology, Boston Children's Hospital and Harvard Medical School, Boston, MA 02115.

The authors declare no competing financial interests.

Correspondence should be addressed to Paola V. Plazas at pvplazas@gmail.com or Ana Belen Elgoyhen at elgoyhen@dna.uba.ar.

https://doi.org/10.1523/JNEUROSCI.1772-20.2020

Copyright $\odot 2021$ the authors 


\section{Introduction}

The processing of external stimuli is essential for all organisms to respond appropriately to environmental cues. Fish and amphibians have a mechanosensory system, the lateral line (LL), which senses hydrodynamic information, crucial for behaviors such as obstacle and predator avoidance, schooling, prey capture, and rheotaxis (Partridge and Pitcher, 1980; Bleckmann and Zelick, 2009; McHenry et al., 2009; Suli et al., 2012; Oteiza et al., 2017). The LL comprises cell clusters, called neuromasts, which are composed of mechanosensitive hair cells (HCs) surrounded by nonsensory cells (Metcalfe et al., 1985). LL HCs transmit sensory information to afferent neurons that project to the hindbrain (Metcalfe et al., 1985; Metcalfe, 1989; Liao, 2010). In addition, they are innervated by descending efferent fibers that modulate LL response to external stimuli (Metcalfe et al., 1985; Bricaud et al., 2001). Anatomical studies in fish revealed two cholinergic efferent nuclei in the hindbrain, and a third dopaminergic nucleus in the forebrain (Hashimoto et al., 1970; Roberts and Russell, 1972; Zottoli and Van Horne, 1983; Tricas and Highstein, 1991; Bricaud et al., 2001). During movement, LL efferent cholinergic modulation aids the animal to distinguish between external and self-generated stimuli, maintaining sensitivity to relevant cues (Lunsford et al., 2019). Although it is known that $\mathrm{D}_{1 \mathrm{~b}}$ receptors mediate neurotransmission at the dopaminergic efferent synapse (Toro et al., 2015), this information is lacking for the cholinergic efferent synapse.

In mammals, the best studied efferent-HC synapse, the cholinergic medial olivocochlear (MOC) efferent system makes direct synaptic contacts with HCs. The net effect of MOC activity is to hyperpolarize HCs (Guinan and Stankovic, 1996) through the activation of $\alpha 9 \alpha 10$ nicotinic acetylcholine receptors (nAChRs). Studies in heterologous systems and in HCs of developing cochlear explants revealed the peculiar functional properties and high calcium $\left(\mathrm{Ca}^{2+}\right)$ permeability of $\alpha 9 \alpha 10$ receptors (Elgoyhen et al., 2001; Gómez-Casati et al., 2005; Ballestero et al., 2011). Subsequent activation of small-conductance $\mathrm{Ca}^{2+}$ activated potassium channel 2 (SK2) drives HC hyperpolarization (Dulon et al., 1998). Although similar molecules are probably expressed in all vertebrate efferent synapses, this information is lacking for LL HCs. However, what has been described for the receptors present at the mammalian efferent-HC synapses might not necessarily apply to other species, since the mammalian $\alpha 9 \alpha 10 \mathrm{nAChR}$ has been under positive selection, rendering a receptor with unique functional properties (Franchini and Elgoyhen, 2006; Lipovsek et al., 2012; Marcovich et al., 2020).

LL HCs share structural, functional, and molecular similarities with those of the cochlea, making them a popular model for studying human hearing and balance disorders (Nicolson, 2005). In particular, efferent stimulation (stim) to the LL and the inner ear leads to the inhibition of afferent transmission (Russell, 1971; Roberts and Russell, 1972; Flock and Russell, 1976; Lunsford et al., 2019; Pichler and Lagnado, 2020), thus suggesting similar synaptic mechanisms. This is most likely brought about by cholinergic efferent fibers (Dawkins et al., 2005; Zhang et al., 2018) directly contacting the base of LL HCs (Dow et al., 2018), similar to what has been described for MOC efferents. Moreover, similar to cochlear outer HCs, LL HCs have a postsynaptic cistern opposed to efferent terminals, which has been proposed to participate in $\mathrm{Ca}^{2+}$ compartmentalization and/or $\mathrm{Ca}^{2+}$-induced $\mathrm{Ca}^{2+}$ release mechanisms (Lioudyno et al., 2004; Fuchs, 2014; Moglie et al., 2018; Zachary et al., 2018). These evidences suggest that the nAChRs at the LL efferent synapse might be composed of $\alpha 9$ and $\alpha 10$ nAChR subunits.
To test this hypothesis, we undertook a multipronged approach, including the analysis of recent single-cell expression studies, the cloning of zebrafish $\alpha 9$ and $\alpha 10 \mathrm{nAChR}$ subunits, and the profiling of the biophysical and pharmacological properties of recombinant $\alpha 9$ and $\alpha 9 \alpha 10$ receptors. In addition, we performed in vivo $\mathrm{Ca}^{2+}$ imaging of zebrafish LL HCs to characterize the physiological signature of the native nAChR. We present strong evidence supporting the notion that the inhibitory signature of the LL efferent cholinergic synapse is most likely served by $\alpha 9$ homomeric receptors and the subsequent activation of $\mathrm{Ca}^{2+}$-dependent SK potassium channels.

\section{Materials and Methods}

Cross-study evaluation of enriched gene expression in zebrafish hair cells. Preprocessed datasets from three single-cell RNA sequencing (RNAseq; Erickson and Nicolson, 2015; Matern et al., 2018; Lush et al., 2019) and one microarray (Steiner et al., 2014) studies that evaluated gene expression in HCs from zebrafish were used (Table 1). Genes were searched by common name and accession number. For all datasets, we used the published normalized and batch-corrected gene relative expression quantification and calculated the differences between HCs and control (Ctrl) cells for each study as the $\log _{2}$ fold change to perform comparisons among studies (Table 2). $p$ Values adjusted for false discovery rate or $q$ values were obtained from each individual study. From the microarray dataset, we used HC versus $\mathrm{mCh}^{+}, \mathrm{GFP}^{+}$mantle data. In the case of the study by Lush et al. (2019), we used mature HCs versus other neuromast cells (including immature HCs)

Cloning of zebrafish $n A C h R$ cDNAs. Zebrafish RNA was isolated from $7 \mathrm{~d}$ postfertilization (dpf) embryos using TRIzol (Thermo Fisher Scientific). mRNA was reverse transcribed using polyT primers with the SuperScript III First-Strand Synthesis System (Thermo Fisher Scientific) to obtain whole-embryo cDNA. Based on the following sequences reported by the Genome Reference Consortium z11, specific primers were designed to amplify whole-zebrafish $\alpha 9$ (ENSDARG00000054680) and $\alpha 10$ (ENSDARG00000011113) nAChR subunits cDNAs: $\alpha 9$ sense (5'-ATG AAG AGC AGT AGC AAA TAA TAA C- $3^{\prime}$ ); $\alpha 9$ antisense (5'-AAT TGC AT AAG TTG TAA AC- $\left.3^{\prime}\right) ; \alpha 10$ sense (5'-ATG ATT TTA TAC TAT ATC C- $\left.3^{\prime}\right) ; \alpha 10$ antisense ( $5^{\prime}$ TCA AAT GGC TTT CCC CAT TAT AAG-3'). Thirty-five cycles were used in both cases with annealing temperatures of $45^{\circ} \mathrm{C}$ and $50^{\circ} \mathrm{C}$ for $\alpha 9$ and $\alpha 10$ subunits, respectively. PCR products were subcloned into pCR2.1-TOPO TA vectors using the TOPO TA Cloning Kit (Thermo Fisher Scientific) and sequenced for verification of correct amplification.

Expression of recombinant receptors in Xenopus laevis oocytes. Zebrafish $\alpha 9$ and $\alpha 10$ cDNAs were subcloned into pSGEM vector, a modified pGEM-HE vector suitable for $X$. laevis oocyte expression studies (Liman et al., 1992). All expression plasmids are readily available on request. Capped cRNAs were transcribed in vitro using the RiboMAX Large Scale RNA Production System-T7 (Promega) from plasmid DNA templates linearized with NheI. Both the maintenance of X. laevis and the preparation and cRNA injection of stage V and VI oocytes, has been described in detail previously (Katz et al., 2000). Typically, oocytes were injected with $50 \mathrm{nl}$ of RNase-free water containing 0.01-1.0 ng of cRNAs and maintained in Barth's solution at $18^{\circ} \mathrm{C}$. A $1: 2 \alpha 9 / \alpha 10$ molar ratio was used to achieve the expression of the heteromeric receptor.

Electrophysiological recordings were performed 2-6d after cRNA injection under two-electrode voltage clamp with a GeneClamp 500B Voltage and Patch Clamp amplifier (Molecular Devices). Data acquisition was performed using a Digidata 1200 and pClamp 7.0 software (Molecular Devices) at a rate of 10 points/s. Both voltage and current electrodes were filled with $3 \mathrm{M} \mathrm{KCl}$ and had resistance of $\sim 0.5-2 \mathrm{M}^{\prime} \Omega$. Data were analyzed using Clampfit from the pClamp 7 software suite (Molecular Devices). During electrophysiological recordings, oocytes were continuously superfused $(10 \mathrm{ml} / \mathrm{min})$ with normal frog saline composed of the following (mM): $115 \mathrm{NaCl}, 2.5 \mathrm{KCl}, 1.8 \mathrm{CaCl}_{2}$ and 10 HEPES buffer, $\mathrm{pH}$ 7.2. Drugs were applied in the perfusion solution of 
Table 1. Meta-data of the studies used to analyze gene enrichment in zebrafish HC

\begin{tabular}{|c|c|c|c|c|c|c|}
\hline Publication & DOl & Age (dpf) & HC promoter & Sorting method & Control & Expression level by \\
\hline Steiner et al. (2014) & 10.1073/pnas.1318692111 & 4 & pou4f3 & FACS & Skin & Microarray \\
\hline Erickson and Nicolson (2015) & $10.1186 / s 12864-015-2072-5$ & 3.5 & my06b & TU-tagging & Non-TU cells & RNAseq \\
\hline Matern et al. (2018) & 10.3389/fcell.2018.00047 & 5 & my06b & RiboTag & Whole larva & RNAseq \\
\hline Lush et al. (2019) & 10.7554/eLife.44431 & 5 & pou4f3 & FACS & Neuromast non-HC & RNAseq \\
\hline
\end{tabular}

Table 2. a9 (but Not a10), SK1a and SK2 are enriched in zebrafish HC

\begin{tabular}{|c|c|c|c|c|c|c|c|c|c|}
\hline \multirow[b]{2}{*}{ Gene } & \multirow[b]{2}{*}{ Ensembl ID } & \multicolumn{2}{|c|}{ Matern et al. (2018) } & \multicolumn{2}{|c|}{ Erickson and Nicolson (2015) } & \multicolumn{2}{|c|}{ Steiner et al. (2014) } & \multicolumn{2}{|c|}{ Lush et al. (2019) } \\
\hline & & $\log _{2} F C$ & Adjusted $p$ value & $\log _{2} F C$ & Adjusted $p$ value & $\log _{2} F C$ & Adjusted $p$ value & $\log _{2} F C$ & Adjusted $p$ value \\
\hline Chrna9 ${ }^{a}$ & ENSDARG00000054680 & 3.655976 & $8.05513 \mathrm{E}-13 *$ & 2.08078 & $0.040471217 *$ & 4.239971 & 4.78929E-11* & 0.892044 & 7.827853E-116* \\
\hline chrna10 & ENSDARG00000011113 & 0.162382 & 1 & -0.15769 & 1 & 0.03275 & 0.849872 & & \\
\hline Kcnn1a ${ }^{a}$ & ENSDARG00000091306 & 1.34144 & $0.001182439 *$ & -0.46363 & 1 & 0.789479 & $0.0218807 *$ & & \\
\hline Kenn1b & ENSDARG00000023546 & 0.120795 & 1 & 0.2286 & 1 & 0.11828 & 0.565259 & & \\
\hline $\operatorname{Kenn} 2^{a}$ & ENSDARG00000014939 & 1.484557 & $0.000490792 *$ & 0.151657 & 1 & 3.958601 & $5.91 \mathrm{E}-06 *$ & & \\
\hline kcnn3 & ENSDARG00000019753 & -0.96006 & 0.413984684 & -0.44232 & 1 & 0.096667 & 0.60571 & & \\
\hline
\end{tabular}

$\log _{2}$ fold change (FC) and adjusted $p$ values for the genes of interest across the different studies analyzed.

${ }^{a} \mathrm{~A}$ gene that shows enrichment of its expression in $\mathrm{HC}$ in at least one of the studies.

*Significant adjusted $p$ value.

the oocyte chamber. The holding potential $\left(V_{\text {hold }}\right)$ was $-70 \mathrm{mV}$ unless otherwise indicated.

To minimize the activation of the $\mathrm{Ca}^{2+}$-sensitive chloride current $\left(\mathrm{ICl}_{\mathrm{Ca}}\right)$ of the native oocyte by $\mathrm{Ca}^{2+}$ entering through nAChRs (Miledi and Parker, 1984; Boton et al., 1989), all experiments were conducted in oocytes preincubated with the membrane permeant $\mathrm{Ca}^{2+}$ chelator bis(2aminophenoxy)ethane- $N, N, N^{\prime}, \mathrm{N}^{\prime}$-tetra-acetic acid (BAPTA)-AM (100 $\mu \mathrm{M})$ for $3 \mathrm{~h}$ before electrophysiological recordings, unless otherwise stated. This treatment was previously shown to effectively chelate intracellular $\mathrm{Ca}^{2+}$ ions and, therefore, to impair the activation of the $\mathrm{ICl}_{\mathrm{Ca}}$ (Gerzanich et al., 1994). Concentration-response curves were obtained by measuring responses to increasing concentrations of ACh.

To assess whether $\mathrm{Ca}^{2+}$ ions are a major component of the inward current on nAChRs, we took advantage of the endogenous $\mathrm{ICl}_{\mathrm{Ca}}$ of the oocyte (Miledi and Parker, 1984; Boton et al., 1989) as an indirect reporter of $\mathrm{Ca}^{2+}$ entry through nAChRs. Current amplitudes were measured in normal frog saline, on the same oocyte before and after a $3 \mathrm{~h}$ incubation in BAPTA-AM. The percentage of the initial response remaining after BAPTA incubation was determined for each oocyte individually. Mean and SEM of the percentage response after BAPTA was then determined for each receptor.

The effects of extracellular $\mathrm{Ca}^{2+}$ on the ionic currents through $n A C h R s$ were studied by measuring the amplitudes of the responses to a near $\mathrm{EC}_{50}$ concentration of $\mathrm{ACh}(\alpha 9,10 \mu \mathrm{M} ; \alpha 9 \alpha 10,300 \mu \mathrm{M})$ on varying the concentration of this cation from nominally $0-3 \mathrm{~mm}$ at a $V_{\text {hold }}$ of $-90 \mathrm{mV}$ (Weisstaub et al., 2002). Amplitude values obtained at each $\mathrm{Ca}^{2+}$ concentration were normalized to that obtained in the same oocyte at $1.8 \mathrm{~mm}$. Values from different oocytes were averaged and expressed as the mean \pm SEM. These experiments were conducted in oocytes injected with $7.5 \mathrm{ng}$ of an oligonucleotide (5'-GCTTTAGTAATTCCCATC CTGCCATGTTTC-3') antisense to connexinC38 mRNA (Arellano et al., 1995; Ebihara, 1996) to minimize the activation of the nonselective inward current of the oocyte through a hemigap junction channel in response to the reduction of the external divalent cation concentration.

Desensitization of ACh-evoked currents was evaluated via a prolonged (1 min) agonist application, at a concentration one order of magnitude above the $\mathrm{EC}_{50}$ for each receptor. The percentage of current remaining $20 \mathrm{~s}$ after the peak of the response was determined for each oocyte. Current-voltage $(I-V)$ relationships were obtained by applying 2 $\mathrm{s}$ voltage ramps from -120 to $+50 \mathrm{mV}$ from a holding potential of -70 $\mathrm{mV}$, at the plateau response to $\mathrm{ACh}$ (at a concentration one order of magnitude below the $\mathrm{EC}_{50}$ for each receptor). Leakage correction was performed by digital subtraction of the $I-V$ curve obtained by the same voltage ramp protocol before the application of ACh.
Zebrafish husbandry and lines. Zebrafish (Danio rerio) were grown at $28.5^{\circ} \mathrm{C}$ on a $14: 10 \mathrm{~h}$ light/dark cycle in $\mathrm{E} 3$ embryo medium (in mM: $130 \mathrm{NaCl}, 0.5 \mathrm{KCl}, 0.02 \mathrm{Na}_{2} \mathrm{HPO}_{4}, 0.04 \mathrm{KH}_{2} \mathrm{PO}_{4}, 1.3 \mathrm{CaCl}_{2}, 1.0 \mathrm{MgSO}_{4}$, and $0.4 \mathrm{NaH}_{2} \mathrm{CO}_{3}$ ). Embryos were obtained from natural spawning and were bred according to guidelines outlined in The Zebrafish Book (Westerfield, 2000). For in vivo imaging and in situ hybridization experiments, $0.2 \mathrm{~mm}$ 1-phenyl2-thiourea was added at $24 \mathrm{~h}$ postfertilization to prevent pigment formation. Animal experiments were performed complying with the Instituto de Investigaciones en Ingeniería Genética y Biología Molecular "Dr. Héctor N. Torres" Institutional Review Board (Animal Care and Use Committee). Larvae were examined at 5-7 dpf unless otherwise stated. At these ages, sex cannot be predicted or determined, and therefore the sex of the animal was not considered in our studies. For mRNA extraction and in situ hybridization studies, wildtype fish of the $\mathrm{AB}$ strain were used. For in vivo $\mathrm{Ca}^{2+}$ imaging experiments, the double-transgenic line Tg [Brn3c:Gal4] [UAS:GCaMP7a] (Xiao and Baier, 2007; Muto et al., 2013) was used.

Whole-mount in situ hybridization. Embryos were fixed at $5 \mathrm{dpf}$ in $4 \%$ paraformaldehyde overnight at $4^{\circ} \mathrm{C}$ and stored at $-20^{\circ} \mathrm{C}$ in $100 \%$ methanol until use. In situ hybridization was performed as described previously (Thisse and Thisse, 2008). To avoid unwanted cross-reaction between nAChR genes, subunit-specific probes were designed in nonconserved regions (intracellular loop of nAChR subunits) using the following primer sets: a9 sense 5'-TGAAAGTGATCGAGGCCCATT-3', a9 antisense $5^{\prime}$-TGTTTTCCACAGACACACCCTG-3', a10 sense $5^{\prime}$ GGACTGCAACTGCAACATGAA-3' and a10 antisense 5'-CACCC TTCCTGTCCTCTTCCT- $3^{\prime}$. Partial sequences of genes of interest were PCR cloned into pCR2.1-TOPO using the Topo TA Cloning Kit (Thermo Fisher Scientific) and used as templates to perform in vitro transcription to synthesize sense and antisense digoxigenin-labeled probes. Sense probes were used as negative controls. Larvae were imaged on a Nikon Eclipse E200 Microscope using a Nikon E. Plan 10×/0.25 numerical aperture objective lens. Images were acquired via a Micrometrics 891CU CCD 8.0 megapixel camera using Micrometrics SE Premium imaging software.

Sample preparation and stimulation for functional imaging. Individual Tg [Brn3c:Gal4;UAS:GcAMP7a] larvae at 5-7 dpf were first anesthetized with tricaine $(0.03 \%$ ethyl 3 -aminobenzoate methanesulfonate salt) and then pinned (through the head and tail) onto a Sylgardfilled recording chamber. To suppress movement, $125 \mu \mathrm{M} \alpha$-bungarotoxin $(\alpha-\mathrm{Btx})$ was injected directly into the heart. This technique is a suitable paralytic for LL recordings, since immunohistochemistry with antibodies against $\alpha$-Btx confirmed the labeling of muscle and did not label HCs of the ear or neuromasts (Trapani and Nicolson, 2010). Larvae 
were then rinsed with extracellular imaging solution (Extra; in mм: 140 $\mathrm{NaCl}, 2 \mathrm{KCl}, 2 \mathrm{CaCl}_{2}, 1 \mathrm{MgCl}_{2}$, and 10 HEPES, pH 7.3, OSM $310 \pm 10$ ) without tricaine and were allowed to recover. Viability was monitored by visually monitoring heart rate and blood flow.

Stimulation of neuromast HCs was accomplished using a custommade fluid jet. Pressure was applied using a $15 \mathrm{ml}$ syringe and controlled through a TTL (transistor-transistor logic) valve system (VC-6 Valve Controller, Warner Instruments) triggered via the recording system. The output was attached to a glass pipette (inner tip diameter, $\sim 30-50 \mu \mathrm{m}$ ) filled with extracellular imaging solution and positioned parallel to the anterior-posterior axis of the fish to mechanically stimulate the apical bundles of HCs along that axis (deflections were sustained for the duration of the stimulus, without flickering and kinocilial deflections were confirmed visually). We used the fluid jet to stimulate the HCs of the two polarities by applying either negative or positive pressure. Air volume injected through the syringe was constant $(5 \mathrm{ml})$ and pressure was controlled with a manometer. Two second square stimuli were delivered to activate HCs of all sensitivities (Zhang et al., 2018; Pichler and Lagnado, 2020).

Functional imaging. Fish were placed into a chamber on the stage of an upright microscope (model BX51WI, Olympus), illuminated with a blue $(488 \mathrm{~nm})$ LED system (Tolket), and images were acquired using an Andor iXon 885 camera controlled through a Till Photonics interface system. The focal plane was located close to the basal region of the neuromast to visualize the basal pole of HCs. The signal-to-noise ratio was improved with a chip binning of $4 \times 4$, giving a resolution of $0.533 \mu \mathrm{m} /$ pixel using a $60 \times$ water-immersion objective. Acquisition rate was set to 6.6 frames/s. Isradipine (Isr), $\alpha$-Btx, and apamin were applied in the bath, and fish were preincubated before image acquisition $(5 \mathrm{~min}$ in the case of isradipine and $1 \mathrm{~min}$ in the case of $\alpha$-Btx and apamin). For ACh experiments, the drug was locally perfused throughout the whole image acquisition protocol (40 s). In the case of coapplication experiments, drugs were first preapplied, as mentioned above, and then coapplied with $\mathrm{ACh}$ throughout the whole image acquisition protocol (40 s). Fluorescence images were processed in FIJI (Schindelin et al., 2012; Rueden et al., 2017) and analyzed with custom-written routines in IgorPro 6.37 (WaveMetrics). Images were motion corrected using the StackReg plugin (Thévenaz et al., 1998). For all experiments, it was corroborated that the local perfusion did not elicit the activation of hair cells.

Regions of interest (ROIs) were hand drawn for each visible $\mathrm{HC}$ in the neuromast. The mean change of fluorescence intensity divided by the control $\left(\Delta F / F_{0}\right)$ was calculated in every ROI for each time frame and corrected for photobleaching by fitting a line between the prestimulus baseline and final fluorescence. Peak fluorescence signals were detected during the mechanical stimulation of the neuromast. Further analysis was performed if the peak signal was at least 2.5 SDs higher than the baseline. For basal fluorescence intensity measurements, larvae were first imaged in extracellular imaging solution for $40 \mathrm{~s}$, then exposed to ACh for $40 \mathrm{~s}$ and a second acquisition was taken. The mean basal fluorescence intensity was calculated and compared for every ROI before and during exposure to ACh.

Statistical analysis. For the biophysical characterization of recombinant receptors in X. laevis oocytes, all plotting and statistical tests were conducted using Prism 6 software (GraphPad Software). Concentration-response curves were normalized to the maximal agonist response in each oocyte. The mean and SEM values of the responses are represented. Agonist concentration-response curves were iteratively fitted with the equation $I / I \max$ $=[A]^{n} /\left([A]^{n}+\mathrm{EC}_{50}{ }^{n}\right)$, where $I$ is the peak inward current evoked by the agonist at concentration $[A]$, Imax is the current evoked by the concentration of agonist eliciting a maximal response, $\mathrm{EC}_{50}$ is the concentration of agonist inducing half-maximal current response, and $n$ is the Hill coefficient.

One-way repeated-measures ANOVA, with a Geisser-Greenhouse correction to account for nonsphericity, was run to determine whether there were statistically significant differences in responses to extracellular $\mathrm{Ca}^{2+}$ concentrations. A Bonferroni multiple-comparison test was performed to evaluate differences between group means.

For in vivo $\mathrm{Ca}^{2+}$ imaging, all experiments were performed on a minimum of eight animals (one neuromast per animal) and on 3 independent days. Plotting and statistical analysis were performed using a custom-written code in Python language (Python 3.7), using pandas, Scipy, numpy, IPython, matplotlib, and seaborn packages (Hunter, 2007; Perez and Granger, 2007; McKinney, 2010; Walt et al., 2011; Virtanen et al., 2020). Normality was tested using a Shapiro-Wilk normality test. As data were not normally distributed, statistical significance between two conditions was determined by Wilcoxon matched-pair ranks test. For this kind of analysis, effect sizes were calculated as Matched Pairs Rank Biserial Correlation (MPRBC), which equals the simple difference between the proportion of favorable and unfavorable evidence (Kerby, 2014). Statistical significance is reported at $\alpha=0.05$

Drugs. All drugs were obtained from Sigma-Aldrich, except $\alpha$-Btx and apamin, which were purchased from Alomone Labs. For in vivo imaging experiments, drugs were brought to their final concentration in normal extracellular imaging solution with $0.1 \%$ DMSO to improve basolateral drug accessibility to LL HCs in whole zebrafish larvae (Trapani and Nicolson, 2011; Sheets et al., 2012, 2017; Toro et al., 2015; Zhang et al., 2018; Wong et al., 2019). Isradipine, apamin, and $\alpha$-Btx were applied in the bath during preincubations and locally perfused. ACh was locally perfused.

\section{Results}

\section{Cross-study evaluation of enriched gene expression in zebrafish hair cells}

To decipher the molecular players at the cholinergic efferent LL synapse, we first studied the expression of genes that encode key molecules of efferent synapses across vertebrates: chrna9 (gene encoding the $\alpha 9 \mathrm{nAChR}$ subunit), chrnal0 ( $\alpha 10$ subunit), and kcnn2 (SK2) in LL HCs. As there is evidence for the expression of other SK channels in zebrafish sensory organs (Cabo et al., 2013), we also evaluated the expression of kcnn1 and kcnn3 (genes encoding SK1 and SK3 channels, respectively). The Genome Reference Consortium Zebrafish Build 11 (GRCz11) indicates two ohnologs for kcnn1 (kcnnla and kcnnlb), and only one copy for chrna9, chrna10, kcnn2, and kcnn3. A previous genome assembly version, GRCz10, had described two ohnologs for both the chrna9 and chrna10 genes, but one of the copies of each gene (ENSDARG00000011029 and ENSDARG00000044353) has been deleted in GRCz11.

We collected data from recently published single-cell RNAseq and microarray studies in zebrafish HCs (Steiner et al., 2014; Erickson and Nicolson, 2015; Matern et al., 2018; Lush et al., 2019; Table 1) and assessed the enrichment of chrna9, chrna10, kcnn $1 \mathrm{a}, \mathrm{kcnn} 1 \mathrm{~b}, \mathrm{kcnn} 2$, and kcnn3 genes. Preprocessed data from each study (normalized, batch corrected, and with their adjusted $p$ values) was analyzed. The relative change in expression ( $\log _{2}$ fold change) in HCs was normalized to the control sample used in each study (Table 2).

Our analysis revealed that only chrna9, kcnn1a, and kcnn2 transcripts are significantly enriched in HCs (Table 2). These observations were true for all datasets analyzed in the case of chrna9 transcripts and in two of the four studies evaluated, in the case of kcnn1a and kcnn2. Surprisingly, chrna10 transcripts showed no enriched expression in HCs (Table 2).

To further analyze the spatial expression pattern of $\alpha 9$ and $\alpha 10$ nAChR subunits, we performed whole-mount in situ hybridization in $5 \mathrm{dpf}$ larvae. To avoid unwanted cross-reaction between $\mathrm{nAChR}$ genes, subunit-specific probes were designed in the nonconserved intracellular loop of nAChR subunits. $\alpha 9$ subunit expression was localized to LL neuromasts and the posterior macula in the otic vesicle (Fig. $1 A-E$ ), confirming its expression in HCs. However, because of spatial resolution, we cannot exclude the possibility that $\alpha 9$ is expressed in supporting cells too. No signal in neuromasts or the otic vesicle was detected for 


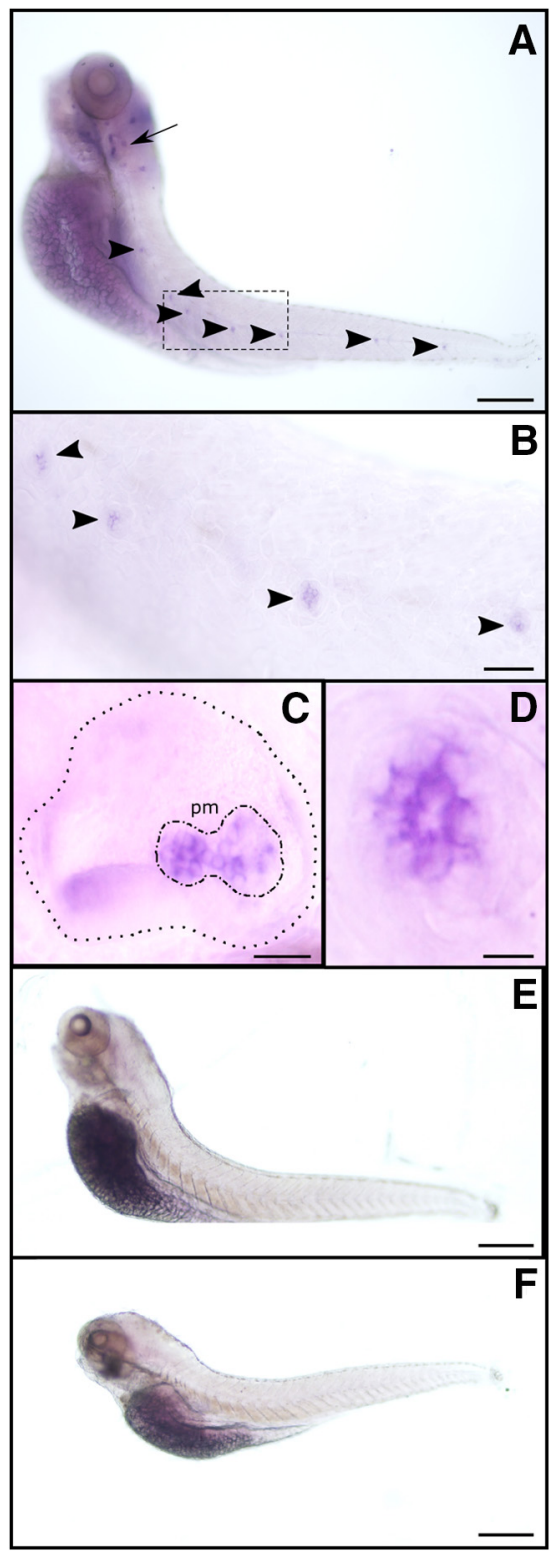

Figure 1. a9 (but not a10) is expressed in zebrafish LL neuromasts and the posterior macula in the otic vesicle. $\boldsymbol{A}-\boldsymbol{F}$, Whole-mount in situ hybridization with antisense $(\boldsymbol{A}-\boldsymbol{D})$ and sense $(\boldsymbol{E}) \mathrm{a}$, and antisense a10 $(\boldsymbol{F})$ riboprobes. Representative lateral views, with anterior to the left and dorsal to the top, are shown. Arrow indicates the otic vesicle, and arrowheads point to selected neuromasts. $\boldsymbol{B}-\boldsymbol{D}$, Large-scale view of the otic vesicle $(\boldsymbol{C})$ and neuromasts $(\boldsymbol{B}, \boldsymbol{D}) . \boldsymbol{C}$, Dotted line delimits the otic vesicle; dotted-dashed line outlines the posterior macula (pm). Scale bars: in $\boldsymbol{A}, \boldsymbol{E}, \boldsymbol{F}, 100 \mu \mathrm{m} ; \boldsymbol{B}, 40 \mu \mathrm{m} ; \boldsymbol{C}, 25 \mu \mathrm{m} ; \boldsymbol{D}, 10 \mu \mathrm{m}$.

the $\alpha 10$ subunit mRNA (Fig. $1 F$ ), indicating that its expression level is null or under the detection limits of this technique. Moreover, we cannot rule out the possibility that the $\alpha 10$ subunit is expressed in LL HCs at later developmental stages.

\section{Biophysical and pharmacological characterization of zebrafish recombinant $\alpha 9$ and $\alpha 9 \alpha 10 \mathrm{nAChRs}$ expressed in Xenopus laevis oocytes}

To determine the possible combinatorial nAChR subunit assemblies leading to functional receptors and to analyze their pharmacological and biophysical properties, we performed RT-PCR with specific primers designed to isolate full-length zebrafish $\alpha 9$ and $\alpha 10 \mathrm{nAChR}$ subunit $\mathrm{cDNAs}$, and subcloned them into pSGEM vector (a pGEM-HE vector optimized for $X$. laevis oocyte expression studies (Liman et al., 1992). In vitro transcribed cRNAs were injected into $X$. laevis oocytes, and responses to $\mathrm{ACh}$ were recorded under two-electrode voltage clamp.

Previous work reported that Rattus norvegicus (rat), Xenopus tropicalis (frog), and Gallus gallus (chicken) $\alpha 9$ subunits can form functional homomeric nAChRs. In contrast, only chicken and frog $\alpha 10$, but not rat subunits, assemble into functional homomeric receptors (Elgoyhen et al., 1994, 2001; Lipovsek et al., 2012, 2014; Marcovich et al., 2020). Whereas zebrafish $\alpha 9$ subunits assembled into functional homomeric receptors leading to robust ACh-evoked currents ( $I \max 425.52 \pm 55.00 \mathrm{nA}, n=$ 28), $\alpha 10$ subunits could not form functional receptors under our experimental conditions (Fig. 2A). Oocytes injected with both $\alpha 9$ and $\alpha 10$ zebrafish cRNAs in an equimolar proportion responded to ACh in a concentration-dependent manner with a two component ACh dose-response curve that corresponds to both homomeric $\alpha 9$ and heteromeric $\alpha 9 \alpha 10$ nAChRs (Fig. 2B). To favor the assembly of $\alpha 9 \alpha 10$ heteromeric receptors and study their properties, we injected both cRNAs in a 1:2 $\alpha 9 / \alpha 10$ ratio. ACh concentration-response curves for homomeric $\alpha 9, \alpha 9 \alpha 10$ (1:1), and $\alpha 9 \alpha 10$ (1:2) nAChRs are shown in Figure 2B. $\alpha 9$ nAChRs exhibited an $\mathrm{EC}_{50}$ of $11.71 \mu \mathrm{M}(n=10$; 95\% CI, 9.4814.46), while the $\mathrm{EC}_{50}$ for $\alpha 9 \alpha 10$ (1:2) receptors was $437 \mu \mathrm{M}$ ( $n=7 ; 95 \% \mathrm{CI}, 357.2-534.6)$. It is interesting to note that, in contrast to that reported for rat receptors, $\alpha 10$ did not boost the responses of the heteromeric $\alpha 9 \alpha 10$ (Imax, 292.05 $\pm 52.13 \mathrm{nA}$; $n=30$ ) compared with the zebrafish homomeric $\alpha 9$ receptor.

\section{Desensitization profile}

A key feature of nAChRs is their desensitization after prolonged exposure to ACh (Quick and Lester, 2002). Zebrafish $\alpha 9$ and $\alpha 9 \alpha 10$ receptors exhibited different desensitization profiles (Fig. 2C). While in the case of the $\alpha 9 \mathrm{nAChR}$ a median of $44 \%$ [interquartile range (IQR), 40.36-50.75\%] of remaining current was observed $20 \mathrm{~s}$ after the peak response to $1 \mathrm{~mm} \mathrm{ACh}$, a median of $14.29 \%$ (IQR, 7.91-17.15\%) was observed for $\alpha 9 \alpha 10$ receptors $20 \mathrm{~s}$ after the peak response to $3 \mathrm{~mm} \mathrm{ACh}$, indicating a faster desensitization ( $* p=7.09 \mathrm{e}-06, U=0.0$, Mann-Whitney test).

\section{Current-voltage relationship}

Another distinctive feature that varies among $\alpha 9 \alpha 10 \mathrm{nAChRs}$ is their $I-V$ relationship. Rat $\alpha 9 \alpha 10$ receptors show a significant outward current at depolarized potentials and a greater inward current at hyperpolarized potentials (Elgoyhen et al., 2001). Chicken $\alpha 9 \alpha 10$ nAChRs exhibit outward currents similar to their rat counterparts, but smaller inward currents (Marcovich et al., 2020), and frog $\alpha 9 \alpha 10$ receptors show an $I-V$ profile with strong inward rectification and almost no outward current at depolarized potentials (Marcovich et al., 2020). Zebrafish $\alpha 9 \alpha 10$ nAChRs also showed a unique $I-V$ profile (Fig. $2 D$ ), exhibiting considerable outward currents at depolarized potentials, similar to chicken $\alpha 9 \alpha 10$ and rat $\alpha 9$ and $\alpha 9 \alpha 10$ receptors (Elgoyhen et al., 2001). At hyperpolarized potentials, although with different amplitudes, both receptors exhibited inward rectification similar to their frog counterpart (Marcovich et al., 2020).

\section{$\mathrm{Ca}^{2+}$ contribution to $\mathrm{ACh}-$ evoked responses}

$\mathrm{Ca}^{2+}$ entry through $\alpha 9 \alpha 10 \mathrm{nAChRs}$ is key for the function of the MOC-HC synapse, since the subsequent activation of $\mathrm{Ca}^{2+}$-dependent potassium channels ultimately leads to the hyperpolarization of the HC. $\mathrm{Ca}^{2+}$ permeability of $\alpha 9 \alpha 10 \mathrm{nAChRs}$ is not uniform across species (Lipovsek et al., 2012, 2014; Marcovich et 
al., 2020). To assess $\mathrm{Ca}^{2+}$ flux through zebrafish $\alpha 9$ and $\alpha 9 \alpha 10$ nAChRs, we analyzed the contribution of the Xenopus oocytes endogenous $\mathrm{ICl}_{\mathrm{Ca}}$ (Miledi and Parker, 1984; Boton et al., 1989) to AChevoked responses. In oocytes expressing a recombinant receptor with high $\mathrm{Ca}^{2+}$ permeability, the $\mathrm{ICl}_{\mathrm{Ca}}$ is strongly activated on ACh application (Barish, 1983). The incubation of oocytes with the membranepermeant fast $\mathrm{Ca}^{2+}$ chelator BAPTA-AM subsequently abolishes the $\mathrm{Cl}^{-}$component of the total measured current (Gerzanich et al., 1994). Responses to ACh showed a strong reduction in peak amplitude after BAPTA incubation (Fig. $3 A ; \alpha 9: 45.05 \pm 5.87 \%$ of peak current remaining, $n=15 ; \quad \alpha 9 \alpha 10$ : $38,97 \pm 5.48 \%$ of peak current remaining, $n=12$ ), indicating a significant $\mathrm{Ca}^{2+}$ contribution to ACh-evoked responses for both receptors.

\section{Modulation of $\mathrm{ACh}$-evoked responses by extracellular $\mathrm{Ca}^{2+}$}

$\alpha 9 \alpha 10$ nAChRs from rat, chicken, and frog exhibit differential modulation by extracellular $\mathrm{Ca}^{2+}$ (Weisstaub et al., 2002; Marcovich et al., 2020). Rat $\alpha 9 \alpha 10$ receptors are both potentiated and blocked by extracellular $\mathrm{Ca}^{2+}$, whereas in the case of frog and chicken $\alpha 9 \alpha 10$ nAChRs ACh responses are only potentiated by this cation. Moreover, rat $\alpha 9$ receptors are blocked only by extracellular $\mathrm{Ca}^{2+}$. To evaluate $\mathrm{Ca}^{2+}$ modulation of zebrafish $\alpha 9$ and $\alpha 9 \alpha 10$ receptors, responses to near $\mathrm{EC}_{50}$ concentrations of $\mathrm{ACh}$ were recorded in normal Ringer's solution at different extracellular $\mathrm{Ca}^{2+}$ concentrations and normalized to the response at $1.8 \mathrm{~mm} \mathrm{Ca}{ }^{2+}$. Strikingly, neither the homomeric $\alpha 9$ nor the heteromeric $\alpha 9 \alpha 10 \mathrm{nAChR}$ responses to ACh were modulated by extracellular $\mathrm{Ca}^{2+}$ (Fig. 3B).

\section{Pharmacological characterization}

A hallmark of $\alpha 9$ and $\alpha 9 \alpha 10$ nAChRs is their peculiar pharmacological profile, which includes $\alpha$-Btx and strychnine (Str) as potent inhibitors. We studied the effect of both drugs on $\alpha 9$ and $\alpha 9 \alpha 10$ nAChRs expressed in Xenopus oocytes. As shown in Figure $4 A$, pre-exposure of oocytes for 1 min with $100 \mathrm{~nm} \alpha$-Btx before the coapplication of $10 \mu \mathrm{M}(\alpha 9)$ or $300 \mu \mathrm{M}(\alpha 9 \alpha 10)$ ACh reduced agonist-evoked response by $94.59 \pm 2.17 \%(n=3)$ and $83.66 \pm 5.50 \%$ $(n=3)$, respectively. A similar block of ACh responses was obtained with strychnine (Fig. 4B). Pre-exposure of oocytes for $1 \mathrm{~min}$ with $1 \mu \mathrm{M}$ Str before the coapplication of $10 \mu \mathrm{M}(\alpha 9)$ or $300 \mu \mathrm{M}(\alpha 9 \alpha 10)$ ACh reduced agonist-evoked response by
A

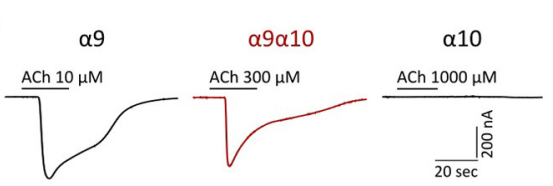

C

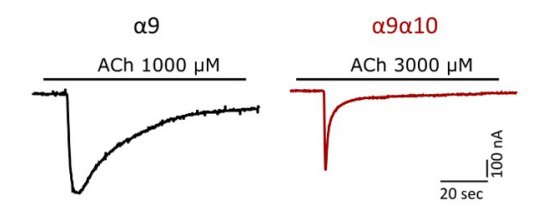

B
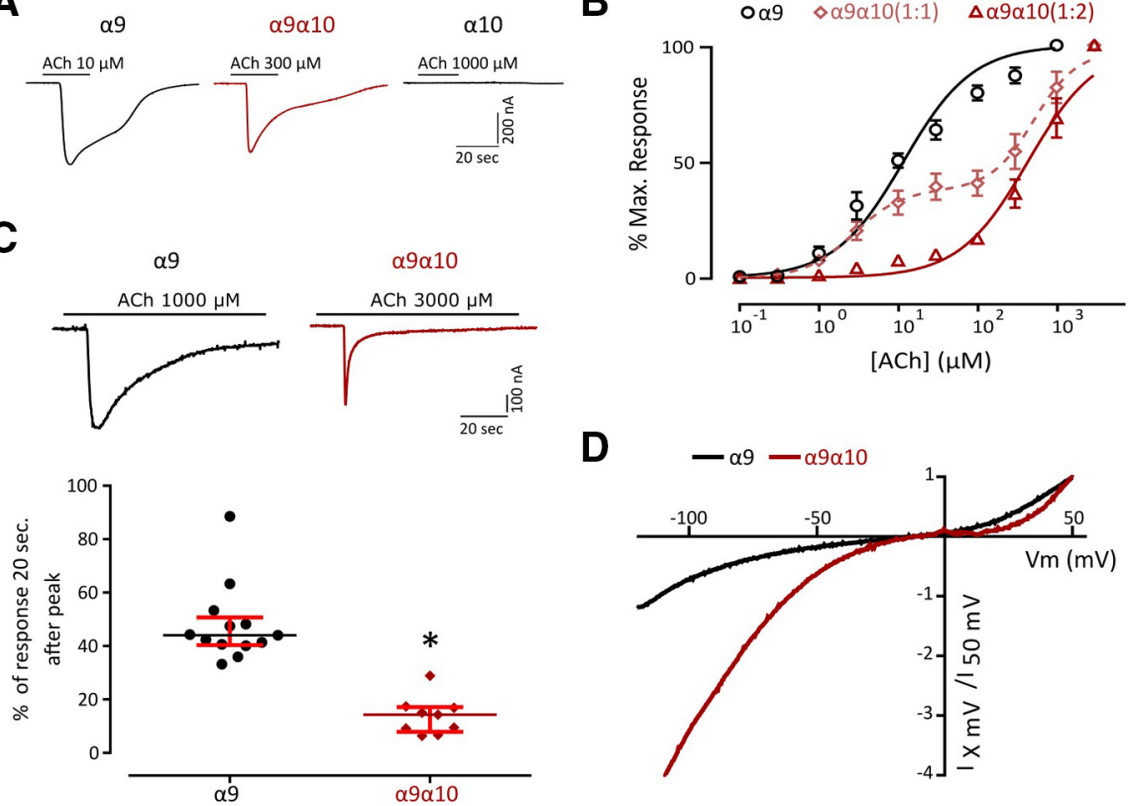

Figure 2. Zebrafish recombinant a9 forms homomeric and heteromeric receptors with a10 with distinct biophysical properties. $A$, Representative responses evoked by ACh in oocytes expressing zebrafish a9, a10, or a9a10 (1:2) nAChRs. $\boldsymbol{B}$, Concentration-response curves for zebrafish a9, a9a10 (1:1), and a9a10 (1:2) nAChRs. Values are the mean \pm SEM. Lines are best fit to the Hill equation. C, Top, Representative responses of zebrafish $\alpha 9$ and $\alpha 9 \alpha 10$ (1:2) nAChRs to a $60 \mathrm{~s}$ application of $\mathrm{ACh}$ (one order of magnitude higher than their corresponding $\mathrm{EC}_{50}$ ). Bottom, Desensitization rate shown as percentage of current remaining $20 \mathrm{~s}$ after the peak response relative to the maximum current amplitude elicited by ACh. Lines indicate the median and IQR. Symbols represent individual oocytes ( $n=13$ and 9, respectively, $* p=7.09 \mathrm{e}-06, \mathrm{U}=0.0$, Mann-Whitney test). $\boldsymbol{D}$, Representative $\mathrm{I}-V$ curves obtained by the application of voltage ramps $(-120$ to $+50 \mathrm{mV}, 2 \mathrm{~s})$ at the plateau response to $10 \mu \mathrm{m}$ ACh for both zebrafish $\alpha 9$ and $\alpha 9 \alpha 10$ (1:2) nAChRs. Values were normalized to the agonist response at $+50 \mathrm{mV}$ for each receptor.

A
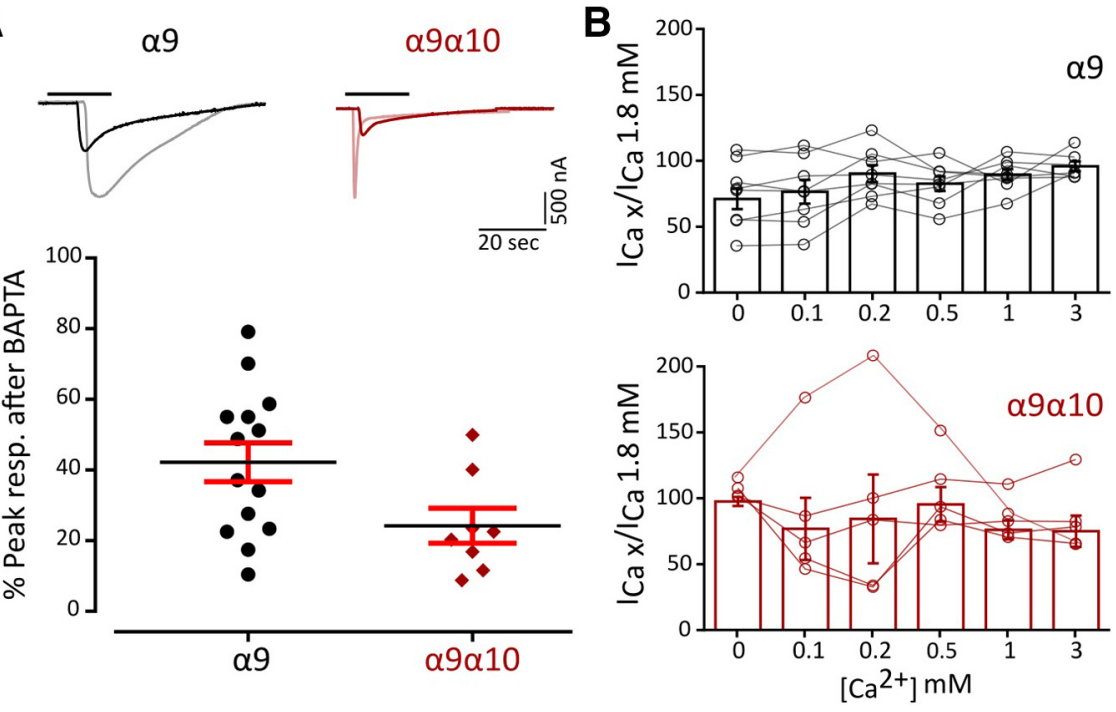

Figure 3. Zebrafish $\alpha 9$ and $\alpha 9 \alpha 10$ nAChRs have a high $\mathrm{Ca}^{2+}$ contribution to the total inward current and are not modulated by extracellular $\mathrm{Ca}^{2+}$. $\boldsymbol{A}$, Top, Representative responses to a near $\mathrm{EC}_{50}$ concentration of $\mathrm{ACh}(\alpha 9,10$ $\mu \mathrm{m} ; \alpha 9 \alpha 10,300 \mu \mathrm{m}$ ) in 0ocytes expressing zebrafish $\alpha 9$ and $\alpha 9 \alpha 10 \mathrm{nAChRs}$ before (light colors) and after (solid colors) a $3 \mathrm{~h}$ incubation with BAPTA-AM. Bottom, Percentage of the initial peak response remaining after BAPTAAM incubation. Lines indicate the median and IQR. Symbols represent individual oocytes $(n=14$ and 8 , respectively), $\boldsymbol{B}, \mathrm{ACh}$ response amplitude as a function of extracellular $\mathrm{Ca}^{2+}$ concentration (top, $\alpha 9$; bottom, $\alpha 9 \alpha 10$ ). ACh was applied at a near $\mathrm{EC}_{50}$ concentration $(\alpha 9,10 \mu \mathrm{m} ; \alpha 9 \alpha 10,300 \mu \mathrm{m})$. Current amplitudes recorded at different $\mathrm{Ca}^{2+}$ concentrations in each oocyte were normalized to the response obtained at $1.8 \mathrm{~mm} \mathrm{Ca}^{2+}$ in the same oocyte ( $\alpha 9$, gray circles; $\alpha 9 \alpha 10$, pink circles). $V_{\text {hold }},-90 \mathrm{mV}$. Bars represent mean $\pm \operatorname{SEM}(\alpha 9$, black bars, $n=8$; $\alpha 9 \alpha 10$, red bars, $n=5)$. 


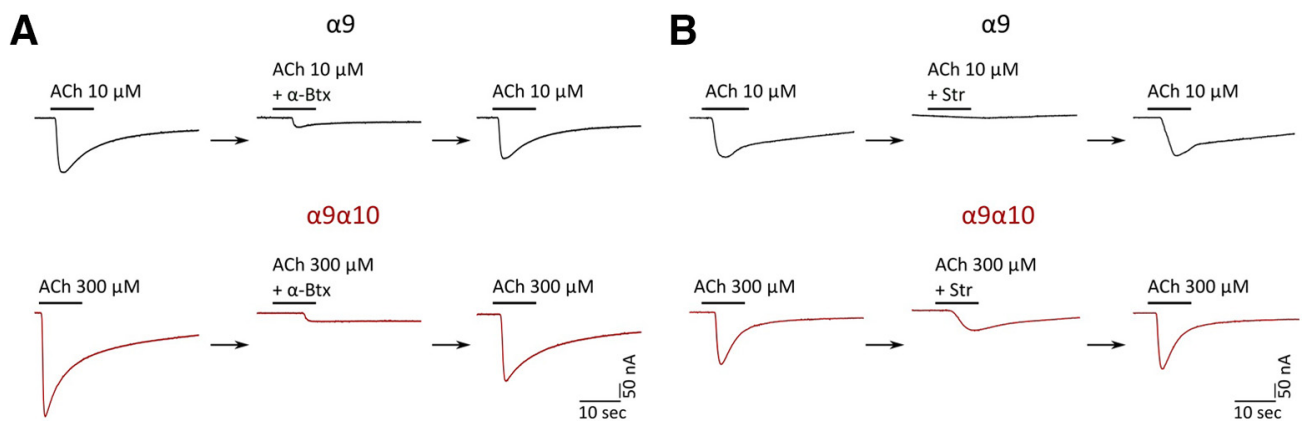

Figure 4. Zebrafish $\alpha 9$ and $\alpha 9 \alpha 10$ nAChRs are reversibly blocked by a-Btx and strychnine. $\boldsymbol{A}, \boldsymbol{B}$, Responses to $10 \mu \mathrm{m}(\alpha 9)$ or $300 \mu \mathrm{m}(\alpha 9 \alpha 10)$ ACh alone, in the presence of $\alpha$-Btx ( $\boldsymbol{A}$ ) or Str $(\boldsymbol{B})$, or after washing with control bath solution for 5 min in oocytes expressing zebrafish $\alpha 9$ or $\alpha 9 \alpha 10 \mathrm{nAChRs}$ are shown. $\boldsymbol{A}, 0$ ocytes were preincubated with $100 \mathrm{~nm} \alpha$-Btx for 1 min before the addition of the agonist. $\alpha$-Btx inhibited ACh-elicited responses through $\alpha 9$ nAChRs by $94.59 \pm 2.17 \%(n=3)$ and through $\alpha 9 \alpha 10$ nAChRs by $83.66 \pm 5.50 \%(n=3)$. $\boldsymbol{B}, 0$ ocytes were preincubated with $1 \mu \mathrm{m}$ Str for 1 min before the addition of ACh. Str inhibited ACh-evoked currents through $\alpha 9$ nAChRs by $95.44 \pm 1.19 \%(n=4)$ and through $\alpha 9 \alpha 10 \mathrm{nAChRs}$ by $57.59 \pm 5.1 \%(n=3)$.

$95.44 \pm 1.19 \%(n=4)$ and $57.59 \pm 5.1 \%(n=3)$, respectively. In all cases, the effects of $\alpha$-Btx and Str were completely reversed by washing the oocytes with frog saline solution for $5 \mathrm{~min}$.

\section{In vivo functional $\mathrm{Ca}^{2+}$ imaging}

To characterize the physiological signature of the native $\mathrm{nAChR}$ present at the zebrafish LL efferent synapse, we performed in vivo $\mathrm{Ca}^{2+}$ imaging in transgenic Tg [Brn3c:Gal4;UAS:GcAMP7a] zebrafish larvae that specifically express the genetically encoded $\mathrm{Ca}^{2+}$ sensor GcAMP7a in HCs. We mechanically stimulated LL HCs with saturating stimuli in both rostral and caudal orientations by applying positive and negative pressure through a pulled glass pipette, respectively, to elicit the activation of the mechanotransduction channel and thus produce depolarization of $\mathrm{HCs}$ and subsequent opening of voltage-gated $\mathrm{Ca}^{2+}$ channels $\left(\mathrm{Ca}_{\mathrm{v}} 1.3 \mathrm{a}\right.$; Zhang et al., 2018; Pichler and Lagnado, 2020). We measured peak fluorescence signals derived from mechanically evoked HC depolarization and subsequent $\mathrm{Ca}^{2+}$ influx through $\mathrm{Ca}_{\mathrm{v}} 1.3 \mathrm{a}$ channels as a proxy of the electrical state of HCs (Fig. $5 A, B$ ). As reported by Wong et al. (2019), LL HCs exhibited variable resting $\mathrm{Ca}^{2+}$ levels $(655.9 \pm 544.05$ A.U., $n=45)$. Posterior LL HCs are also variable in their function and signal transduction properties (Zhang et al., 2018; Pichler and Lagnado, 2020). We therefore chose as our experimental unit single HCs that were selective for one polarity; that is, HCs that showed robust activation either by positive or negative deflections (Fig. $5 B$, cells $1,2,3,4$, 5,8 , and 9). HCs exhibited robust and stable $\mathrm{Ca}^{2+}$ signals over two trials with the same stimulation after $1 \mathrm{~min}$ (Fig. $5 C ; 1^{\circ}$ stim: median $\Delta F / F_{0}=0.858$; IQR, $0.472-1.504$; vs $2^{\circ}$ stim: median $\Delta F / F_{0}=0.876$; IQR, 0.475-1.503, $n=113, W=-835, p=$ $0.2317, \mathrm{MPRBC}=0.129$; Wilcoxon matched-pairs signed-rank test). Consistent with previous findings (Sheets et al., 2012; Zhang et al., 2018), HCs pretreated with the $\mathrm{Ca}_{\mathrm{v}} 1.3$ antagonist isradipine $(10 \mu \mathrm{M})$ showed a significant decrease in $\mathrm{Ca}^{2+}$ entry levels with respect to control conditions (Fig. 5D; Ctrl: median $\Delta F / F_{0}=0.743$; IQR: $0.249-1.086$; vs Isr: median $\Delta F / F_{0}=0.209$; IQR, 0.079-0.433; $n=23 ; W=-258 ; p=8.726 \mathrm{e}-05 ; \mathrm{MPRBC}=$ 0.935 ; Wilcoxon matched-pairs signed-rank test). This finding reveals that under our experimental conditions a large proportion of the total change in fluorescence intensity after mechanical stimulation can be attributed to $\mathrm{Ca}^{2+}$ influx through $\mathrm{Ca}_{\mathrm{v}} 1.3 \mathrm{a}$ channels. The remaining change in fluorescence intensity is most likely because of $\mathrm{Ca}^{2+}$ entering through the mechanotransduction channel (Zhang et al., 2018).

Stimulation of cholinergic efferents in the LL of Xenopus, burbot Lota lota, and dogfish Scyliorhynus inhibits spontaneous and evoked activity of afferents by generating IPSPs in HCs (Russell, 1971; Roberts and Russell, 1972; Flock and Russell, 1976). In zebrafish, the activation of cholinergic efferents suppresses glutamate release from HCs (Pichler and Lagnado, 2020) and inhibits afferent activity (Lunsford et al., 2019). This most likely results from ACh-evoked hyperpolarization of $\mathrm{HCs}$ and reduced $\mathrm{Ca}^{2+}$ influx through voltage-activated $\mathrm{Ca}^{2+}$ channels.

To analyze the effect of nAChR activation on HCs, we evaluated the change in fluorescence intensity on mechanically stimulated HCs pretreated with ACh. If the activation of $\mathrm{nAChR}$ leads to HC hyperpolarization, then exogenous application of ACh should result in a decreased change in fluorescence intensity because of a reduced activation of $\mathrm{Ca}_{\mathrm{v}} 1.3$ channels and thus lower $\mathrm{Ca}^{2+}$ influx. As expected, exogenous application of $1 \mathrm{~mm}$ ACh on mechanically stimulated HCs elicited a significant decrease in evoked $\mathrm{Ca}^{2+}$ influx with respect to control (Fig. 6A,B; Ctrl: median $\Delta F / F_{0}=0.818$; IQR, 0.341-1.479; vs ACh: median $\Delta F / F_{0}=0.573$; IQR, $0.315-1.101 ; n=114 ; W=-3493 ; p=7.89 \mathrm{e}-$ 07; $\mathrm{MPRBC}=0.532$; Wilcoxon matched-pairs signed-rank test). This effect was reversed by superfusing the preparation with extracellular imaging solution (Fig. $6 C ; n=37$; Friedman test: $Q=18.54, p=9.418 \mathrm{e}-05$; Dunn's multiple-comparisons test: Extra vs ACh, $p=0.000705$; Extra vs Wash, $p=0.608054)$. ACh application per se did not evoke changes in basal fluorescence intensity (Fig. 6D; naive, $655.9 \pm 81.1$ A.U.; versus ACh, $652.2 \pm$ 78.55 A.U.; $n=45$ cells, $t=0.7816, \mathrm{df}=44, p=0.4386$, two-tailed paired $t$ test). Furthermore, ACh-mediated effect was observed in $\mathrm{HCs}$ regardless of polarity. Figure $6 \mathrm{E}$ shows that exogenous application of ACh elicited a significant decrease in mechanically evoked $\mathrm{Ca}^{2+}$ influx, both in HCs selectively activated by an anterior to posterior (Ant-Post) or by a posterior to anterior (PostAnt) stimulus (Ant-Post: Extra median $\Delta F / F_{0}=0.783$; ACh median $\Delta F / F_{0}=0.559 ; n=62 ; W=-1227 ; p=1.698 \mathrm{e}-05 ; \mathrm{MPRBC}=$ 0.628; Post-Ant: Extra median $\Delta F / F_{0}=0.831$; ACh median $\Delta F / F_{0}=0.653 ; n=52 ; W=-582 ; p=0.008 ; \mathrm{MPRBC}=0.422$; Wilcoxon matched-pairs signed-rank test). In addition, there was no significant difference in the magnitude of ACh-mediated effect between HCs with different polarity selectivity (Fig. 6F; Ant-Post median relative $\Delta F / F_{0}$ difference $=-0.2003$; IQR, -0.424 to 0.051 ; vs Post-Ant median relative $\Delta F / F_{0}$ difference $=-0.241$ IQR, -0.497 to $0.118 ; U=1560, p=0.7687$; Mann-Whitney test). It is noteworthy that the ACh-mediated effect on evoked $\mathrm{Ca}^{2+}$ signals was heterogeneous. To quantify the degree of inhibition elicited by $\mathrm{ACh}$, we used an ad hoc metric, the inhibition index (II) that was calculated for each $\mathrm{HC}$ in Figure $6 A$. If $\Delta F / F_{0 \text { extra }}$ is the change in fluorescence intensity on mechanically stimulated 
HCs under control conditions and $\Delta F / F_{0 A C h}$ is the change in fluorescence intensity on mechanically stimulated $\mathrm{HC}$ pretreated with $\mathrm{ACh}$, then II was calculated as follows:

$$
I I=\frac{\frac{\Delta F}{F 0_{\text {Extra }}}-\frac{\Delta F}{F 0_{A c h}}}{\frac{\Delta F}{F 0_{\text {Extra }}}} .
$$

Thus, $\mathrm{II}=0$ indicates no inhibition, $\mathrm{II}=1$ indicates full inhibition, and $0<$ II $<1$ indicates partial inhibition. Figure $6 G$ shows the distribution of II for AChtreated HCs. As expected, in the majority of cases II values were $>0$. However, a subpopulation of cells exhibited II values close to 0 , denoting no ACh-mediated inhibition. The absence of ACh-treated HCs with $\mathrm{II}=1$ is a consequence of our selection criteria (i.e., selecting cells with measurable mechanically evoked $\mathrm{Ca}^{2+}$ signals in both control conditions and during ACh treatment). Consequently, the inhibitory effect of ACh might be underestimated.

To assess the identity of the nAChR mediating synaptic transmission at the LL efferent synapse, we tested the effect of $\alpha$-Btx, a potent inhibitor of recombinant zebrafish $\alpha 9$ and $\alpha 9 \alpha 10$ nAChRs, on ACh-mediated inhibition of evoked $\mathrm{Ca}^{2+}$ signals. Figure $7 B$ shows that ACh modulation was blocked when this agonist was coapplied with $10 \mu \mathrm{M} \alpha$-Btx ( $\alpha$-Btx: median $\Delta F / F_{0}=0.534$; IQR, 0.3308-1.325; vs ACh- $\alpha$-Btx: median $\Delta F / F_{0}=0.4015$; IQR, $0.203-0.816 ; n=25 ; W=-87, p=0.2541$; $\mathrm{MPRBC}=0.268$; Wilcoxon matched-pairs signed-rank test), supporting the hypothesis that a functional $\alpha 9 * \mathrm{nAChR}$ is present at the zebrafish LL efferent synapse.

In mammals and birds, the inhibitory sign of the efferent synapse is because of the entry of $\mathrm{Ca}^{2+}$ through $\alpha 9 \alpha 10$ receptors and the subsequent activation of a small-conductance SK2 $\mathrm{Ca}^{2+}$-dependent potassium channel (Hiel et al., 2000; Oliver et al., 2000; Gómez-Casati et al., 2005; Matthews et al., 2005; Elgoyhen and Katz, 2012). To evaluate the coupling of ACh responses to SK channel activation in zebrafish LL efferent synapse, we analyzed the effect of apamin, a known SK channel blocker (Yamamoto et al., 1997), on ACh-mediated inhibition of evoked $\mathrm{Ca}^{2+}$ signals. Coapplication of $1 \mathrm{~mm} \mathrm{ACh}$ and $10 \mu \mathrm{M}$ apamin abolished the inhibitory effect of ACh (Fig. 7D; Apa: median $\Delta F / F_{0}=0.470$; IQR, 0.176-0.818; vs Apa-ACh: median $\Delta F /$ $F_{0}=0.508 ; \mathrm{IQR}, 0.192-0.718 ; n=60 ; W=-322 ; p=0.2359$; $\mathrm{MPRBC}=0.1759$; Wilcoxon matched-pairs signed-rank test), suggesting that the $\mathrm{nAChR}$ that serves the LL efferent synapse is functionally coupled to an SK channel.

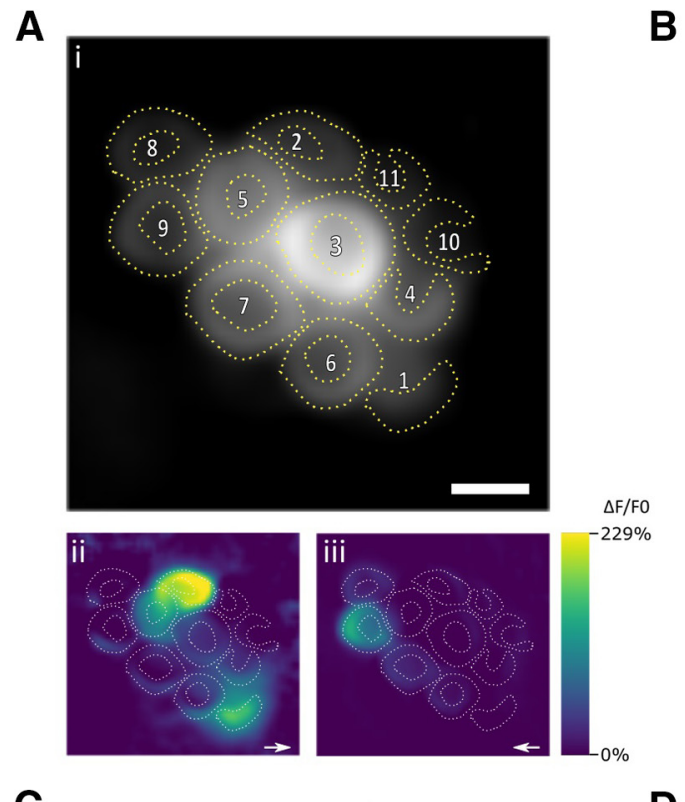

B
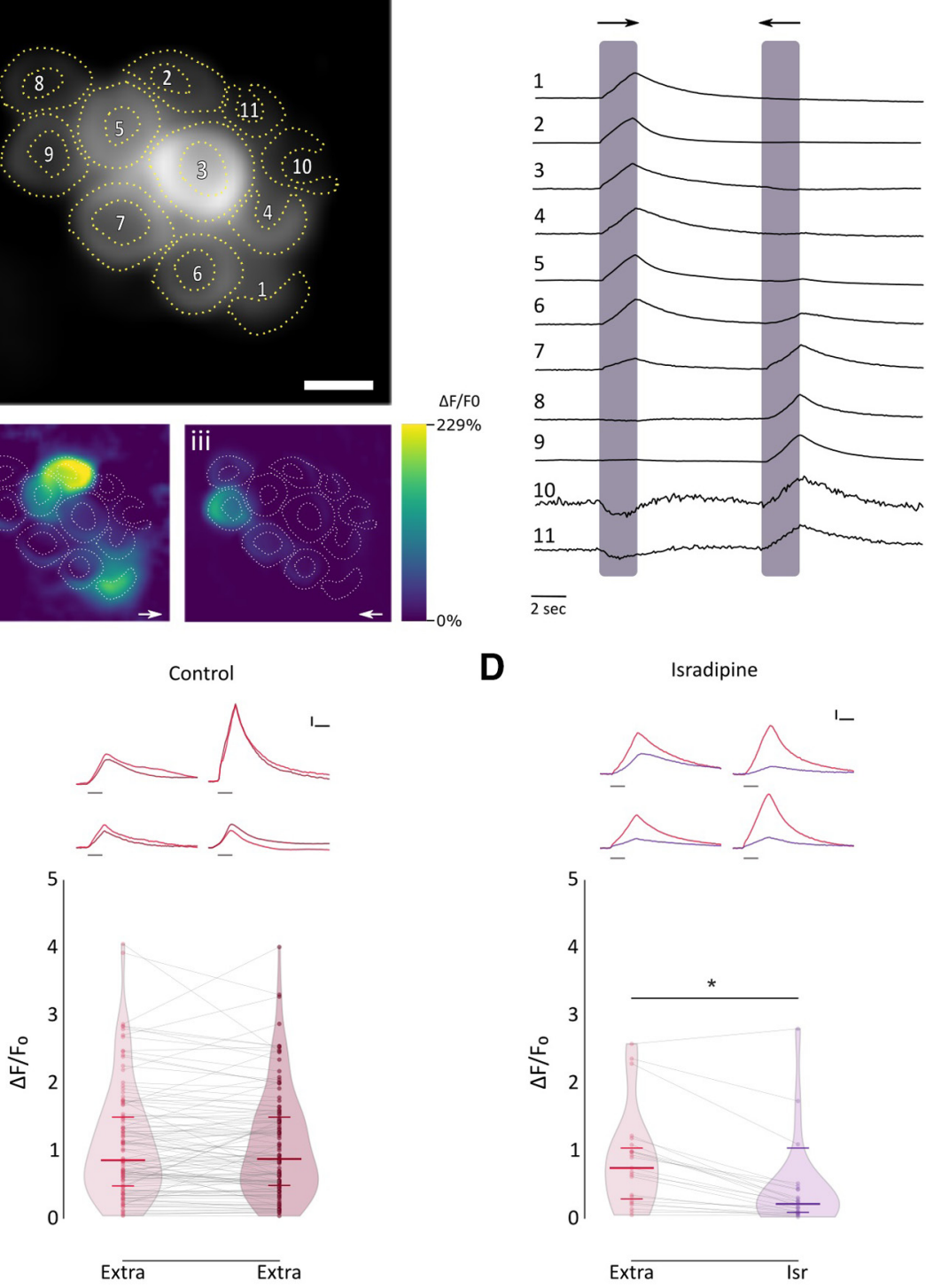

Figure 5. Mechanical stimulation elicits a robust $\mathrm{Ca}^{2+}$ signal that is inhibited by isradipine $\boldsymbol{A}$, Representative functional $\mathrm{Ca}^{2+}$ images of a double-transgenic neuromast expressing GCAMP7a in HCs. A, Prestimulus baseline grayscale image (ROls are drawn around each visible hair cell; $i$ ), spatial patterns of $\mathrm{GCaMP7a}^{2+} \mathrm{C}^{2+}$ signals (ii, iii), during a $2 \mathrm{~s}$ mechanical stimulus in either the anterior-posterior $(\rightarrow)$ or in the posterior-anterior direction $(\leftarrow)$, are color coded according to the $\Delta F / F_{0}$ heat map. $\boldsymbol{B}$, Representative temporal curves of mechanosensitive $\mathrm{Ca}^{2+}$ responses $\left(\Delta F / F_{0}\right)$ of $\mathrm{HCs}$ numbered in $\boldsymbol{A}$, normalized to the peak intensity for each cell. Shaded areas indicate the time when the neuromast was mechanically stimulated. $C$, Top, Representative temporal $\Delta F / F_{0}$ curves of mechanosensitive $\mathrm{Ca}^{2+}$ responses of four $\mathrm{HCs}$ over two trials with the same stimulation after $1 \mathrm{~min}\left(1^{\circ}\right.$ stimulus, light red; $2^{\circ}$ stimulus, dark red). Curves are aligned to the onset of the mechanical stimulus. Bottom, Peak $\Delta F / F_{0}$ for single HCs ( $n=113$, each in its preferred orientation) over two trials with the same stimulation 1 min apart. $D$, Top, Representative temporal $\Delta F / F_{0}$ curves of mechanosensitive $\mathrm{Ca}^{2+}$ responses of four $\mathrm{HCs}$ before (red) and after (purple) preincubation with $10 \mu \mathrm{m}$ isradipine. Curves are aligned to the onset of the mechanical stimulus. Bottom, Preincubation with $10 \mu \mathrm{m}$ isradipine drastically reduced peak $\Delta F / F_{0}(n=23, W=-258, * p=8.726 \mathrm{e}-05, \mathrm{MPRBC}=0.935$; Wilcoxon matched-pairs signed-rank test). Scale bar, $A, 5 \mu \mathrm{m}$. Calibration: $\boldsymbol{C}, \boldsymbol{D}, 1.5 \mathrm{~s} ; \boldsymbol{C}, \mathbf{D}, 25 \% \Delta F / F_{0}$. Duration of the stimulus in $\boldsymbol{C}$ and $\boldsymbol{D}$ top, is indicated by gray lines below each trace.

\section{Discussion}

Vertebrate HC systems are innervated by efferent fibers that modulate their response to external stimuli (Russell, 1971; Metcalfe et al., 1985; Guinan and Stankovic, 1996; Bricaud et al., 2001). In the LL, the excitation of efferent fibers inhibits afferent activity by generating IPSPs in HCs (Russell, 1971; Flock and Russell, 1973, 1976). In addition, excitatory efferent effects, mediated by dopamine acting through $\mathrm{D}_{1 \mathrm{~b}}$ receptors (Toro et al., 2015), can be observed when cholinergic transmission is blocked 
A
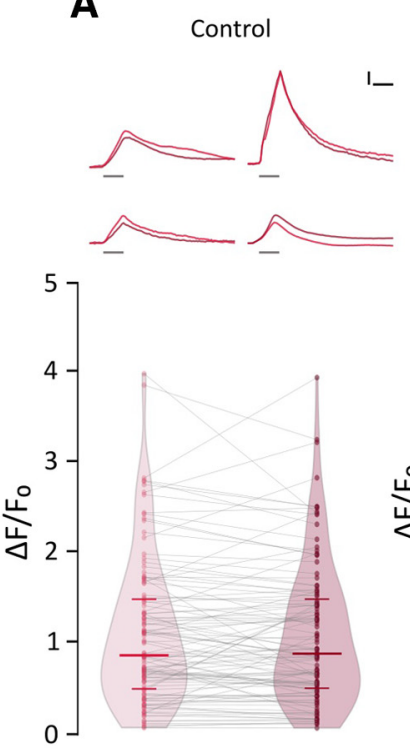

Extra Extra

E

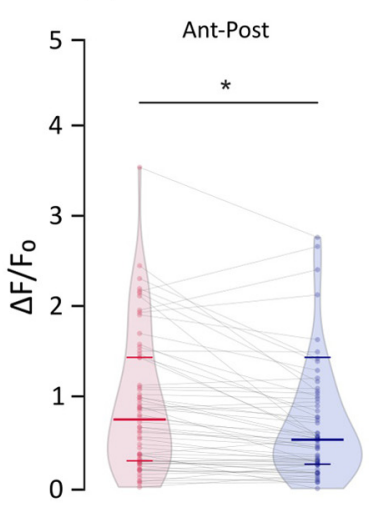

Extra $\quad \mathrm{ACh}$

G

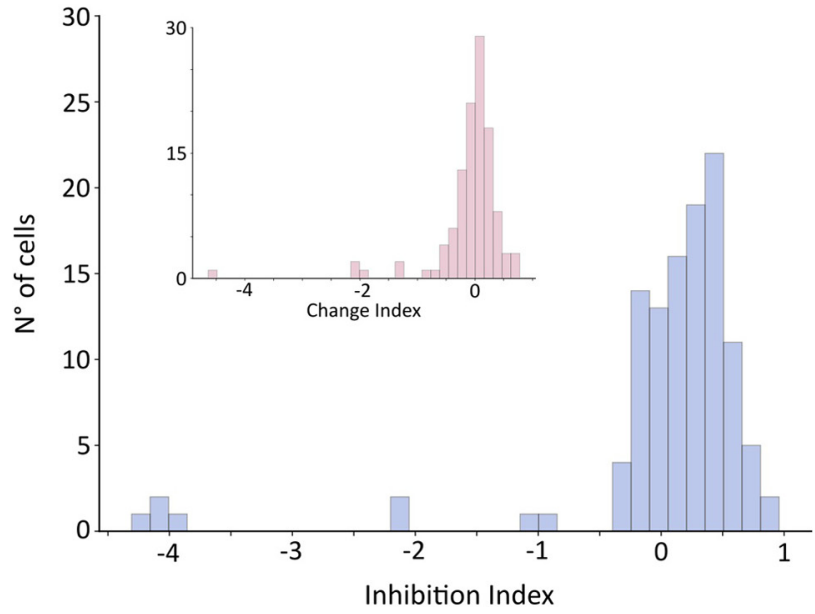

C

Acetylcholine
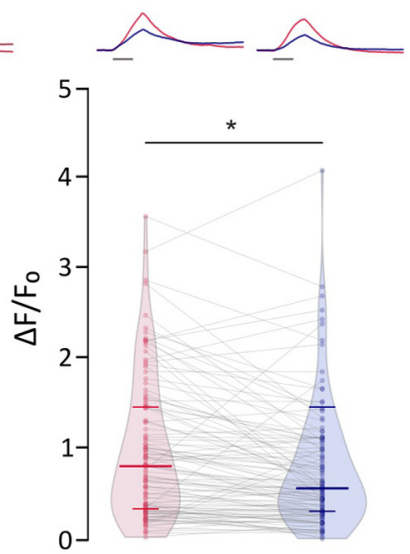

Extra $\quad$ ACh

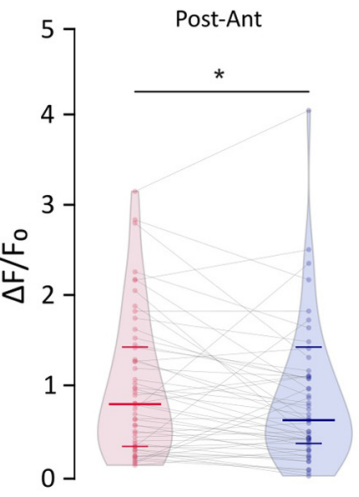

Extra $\quad$ ACh

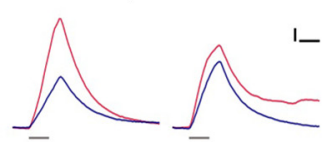

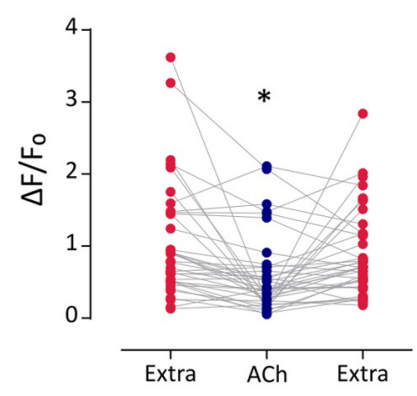

D

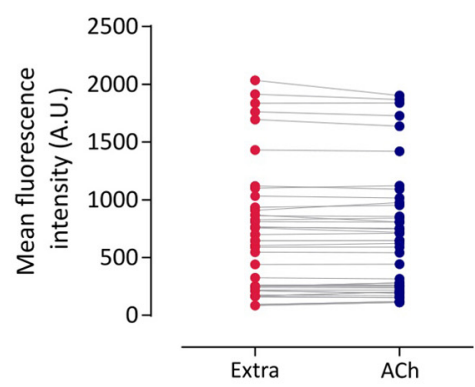

$\mathbf{F}$

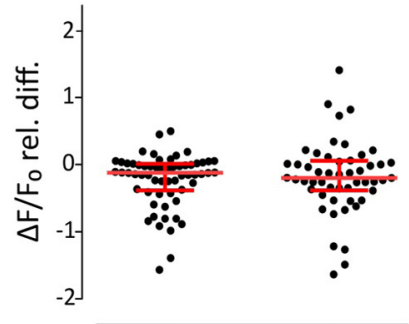

Ant-Post Post-Ant

Figure 6. ACh inhibits mechanically evoked $\mathrm{Ca}^{2+}$ signals, and this inhibition is heterogeneous and independent of $\mathrm{HC}$ polarity $A$, Top, Representative temporal $\Delta F / F_{0}$ curves of mechanosensitive $\mathrm{Ca}^{2+}$ responses of four $\mathrm{HCs}$ over two trials with the same stimulation $1 \mathrm{~min}$ apart $\left(1^{\circ}\right.$ stimulus, light red; $2^{\circ}$ stimulus, dark red). Curves are aligned to the onset of the mechanical stimulus. Bottom, Peak $\Delta F / F_{0}$ for single HCs $(n=113)$ over two trials with the same stimulation after $1 \mathrm{~min}$. $\boldsymbol{B}$, Top, Representative temporal $\Delta F / F_{0}$ curves of mechanosensitive $\mathrm{Ca}^{2+}$ responses of four HCs before (red) and after (blue) the application of $1 \mathrm{~mm}$ ACh. Curves are aligned to the onset of the mechanical stimulus. Bottom, ACh application reduces mechanosensitive $\mathrm{Ca}^{2+}$ responses $\left(n=114, W=-3493, * p=7.89 \mathrm{e}-07, \mathrm{MPRBC}=0.532\right.$, Wilcoxon matched-pairs signed-rank test). $C$, ACh-mediated reduction in mechanically evoked $\mathrm{Ca}^{2+}$ signals is reversed after 
(Flock and Russell, 1973). To date, the molecular players serving ACh-mediated inhibitory effects remain unknown. Here we provide evidence for a mechanism in which an $\alpha 9 * \mathrm{nAChR}$ operates at the zebrafish LL efferent synapse. Our study suggests that $\mathrm{Ca}^{2+}$ influx through these receptors activates nearby SK channels, leading to LL HC hyperpolarization (Fig. 8).

Efferent innervation mediated by $\alpha 9 *$ nAChRs is a feature common to all known vertebrate HCs (Elgoyhen et al., 1994; Glowatzki and Fuchs, 2000; Hiel et al., 2000; Holt et al., 2003; Parks et al., 2017). In mammals, MOC efferent activity is mediated by $\alpha 9 \alpha 10 \mathrm{nAChRs}$ (Elgoyhen et al., 2001; Lustig et al., 2001; Sgard et al., 2002; Gómez-Casati et al., 2005). Moreover, $\alpha 10$ subunits are strictly required for efferent function, since $\alpha 9$ nAChRs expressed in $\alpha 10^{-1-}$ mice are unable to drive efferent signals (Vetter et al., 2007). Surprisingly, our analysis of previous single-cell studies (Table 2) and in situ hybridization data showed enriched expression of $\alpha 9$ but not $\alpha 10$ subunits in zebrafish HCs. Furthermore, our functional data proved that zebrafish $\alpha 9$ nAChRs expressed in Xenopus oocytes exhibit robust AChevoked currents, which are not boosted in magnitude when coexpressed with $\alpha 10$. This is in stark contrast to the data observed for heterologously expressed rat $\alpha 9$ receptors, which exhibit very small ACh-evoked responses, which are nonreliable and are significantly boosted when coexpressed with $\alpha 10$ (Elgoyhen et al., 1994, 2001; Sgard et al., 2002). Therefore, our expression and functional data strongly suggest that an $\alpha 9$ homomeric $\mathrm{nAChR}$ operates at the LL efferent synapse.

Striking features of the zebrafish $\alpha 9 \mathrm{nAChR}$ are its high desensitization rate and lack of modulation by external $\mathrm{Ca}^{2+}$. This differs from those reported for rat (Elgoyhen et al., 1994; Katz et al., 2000) and chicken (Lipovsek et al., 2012) $\alpha 9$ receptors, since both exhibit low desensitization kinetics, and rat receptors (not reported for chicken) are blocked by extracellular $\mathrm{Ca}^{2+}$. These results support the observation that within the nAChR family, $\alpha 9$ and $\alpha 10$ subunits exhibit the highest degree of coding sequence divergence, mirrored by a great variability of functional properties across species (Franchini and Elgoyhen, 2006; Lipovsek et al., 2012; Marcovich et al., 2020).

Differences in nAChR abundance and/or localization and anatomic arrangement of efferent terminals contacting HCs might exist between fish and mammals. However, as reported for cochlear HCs (Moglie et al., 2018), $\mathrm{Ca}^{2+}$ homeostasis is probably a key feature of LL efferent-HC synapses. The high desensitization kinetics of zebrafish $\alpha 9 *$ receptors probably lead to a self-limiting

\section{$\leftarrow$}

a 1 min wash with extracellular imaging solution $(n=37$; Friedman test: $F=18.54$, $p=9.418 \mathrm{e}-05$; Dunn's multiple comparisons test: Extra vs ACh, $* p=0.000705$; Extra vs Wash, $p=0.608054)$. $D$, Basal $\mathrm{Ca}^{2+}$ levels show no significant differences before and during the application of $1 \mathrm{~mm} \mathrm{ACh} \mathrm{(} n=45$ cells, $t=0.7816, \mathrm{df}=44, p=0.4386$, two-tailed paired $t$ test). $\boldsymbol{E}$, ACh reduces mechanosensitive $\mathrm{Ca}^{2+}$ responses in $\mathrm{HCs}$ of opposing polarity (AntPost: $n=62, W=-1227, * p=1.698 \mathrm{e}-05, \mathrm{MPRBC}=0.628$; Post-Ant: $n=52, W=$ $-582, * p=0.008$, MPRBC $=0.422$; Wilcoxon matched-pairs signed-rank test). $F$, HCs of opposing polarity exhibit no significant differences between their ACh-mediated relative change in peak $\Delta F / F_{0}(U=1560, p=0.7687$, Mann-Whitney test). $G$, Distribution of II calculated as $\left(\Delta F / F_{0}\right.$ extra $\left.-\Delta F / F_{0} A C h\right) / \Delta F / F_{0}$ extra) for ACh-treated $H C$. Inset, Distribution of change index [calculated as $\left(\Delta F / F_{0} s t i m 1-\Delta F / F_{0} s t i m 2\right) / \Delta F / F_{0} s$ tim1] for two successive mechanical stimuli under control conditions. The distribution of the change index is centered around 0 . A reduced number of cells $(<10 \%)$ exhibit large negative change index values that occur when the fluorescence signal is greater during the $2^{\circ}$ stimulus, suggesting that these might be outliers. Lines inside violin plots in $\boldsymbol{A}, \boldsymbol{B}$ and $\boldsymbol{E}$ indicate the median and IQR. Calibration: $\boldsymbol{A}, \boldsymbol{B}, 1.5 \mathrm{~s} ; \boldsymbol{A}, \boldsymbol{B}, 25 \% \Delta F / F_{0}$. Duration of the stimulus in $\boldsymbol{A}$ and $\boldsymbol{B}$, top, is indicated by gray lines below each trace.
$\mathrm{Ca}^{2+}$ entry through this highly $\mathrm{Ca}^{2+}$-permeable nAChR. As reported for developing inner HCs (Moglie et al., 2018), this is key to prevent cross talk between efferent and afferent systems, which coexist in LL HCs, and could lead to $\mathrm{Ca}^{2+}$ spillover from efferentmediated $\mathrm{Ca}^{2+}$ entry to $\mathrm{Ca}^{2+}$-triggered glutamate release and activation of afferent fibers. Furthermore, as for cochlear HCs (Moglie et al., 2018), postsynaptic cisterns opposed to LL efferent terminals (Dow et al., 2018) could also aid in preventing efferent-to-afferent cross talk. In rat and chicken, the desensitization capability of $\alpha 9 \alpha 10$ receptors is provided by the $\alpha 10$ subunit (Elgoyhen et al., 2001; Lipovsek et al., 2012). Since in zebrafish LL the efferent response most likely relies on $\alpha 9 \mathrm{nAChRs,} \mathrm{one} \mathrm{could} \mathrm{propose} \mathrm{that}$ substitutions in the coding sequence of this subunit might have led to a receptor highly fitted to convey self-limiting $\mathrm{Ca}^{2+}$ influx into HCs, and this should be further tested.

The increase in intracellular $\mathrm{Ca}^{2+}$ on deflection of the cilia, results from $\mathrm{Ca}^{2+}$ influx through mechanosensitive ion channels (Corey and Hudspeth, 1979; Fettiplace, 2009; Zhang et al., 2018) and the subsequent activation of voltage-gated $\mathrm{Ca}^{2+}$ channels because of HC depolarization (Moser and Beutner, 2000; Sheets et al., 2017; Zhang et al., 2018). The fact that the application of $\mathrm{ACh}$ resulted in a reduction of $\mathrm{Ca}^{2+}$ signals most likely indicates a reduced depolarization. Thus, one could propose that $\mathrm{ACh}$ inhibits $\mathrm{Ca}^{2+}$ influx because of a net hyperpolarization of LL HCs. The finding that ACh-mediated effect can be blocked by apamin supports the generally held hypothesis that $\mathrm{Ca}^{2+}$ entering through the efferent $\mathrm{nAChR}$ activates nearby SK channels leading to HC hyperpolarization (Doi and Ohmori, 1993; Blanchet et al., 1996; Nenov et al., 1996; Yuhas and Fuchs, 1999; Glowatzki and Fuchs, 2000; Oliver et al., 2000; Holt et al., 2003, 2003; Katz et al., 2004; Dawkins et al., 2005; Gómez-Casati et al., 2005; Parks et al., 2017). In birds (Matthews et al., 2005) and mammals (Dulon et al., 1998; Oliver et al., 2000), $\alpha 9 *$ nAChRs are functionally coupled to SK2 $\mathrm{K}^{+}$channels. However, our cross-study analysis revealed that both kcnn2 (SK2) and kcnn1b (SK1b) transcripts are enriched in zebrafish HCs. This is consistent with the study by Cabo et al. (2013), which showed SK1 expression in zebrafish LL HCs. Interestingly, SK1 and SK2 are generally coexpressed in the brains of fish (Ellis et al., 2008) and mammals (Stocker and Pedarzani, 2000; Sailer et al., 2004). Moreover, rat SK1 forms functional heteromeric channels with SK2 (Benton et al., 2003; Autuori et al., 2019). The fact that apamin blocked ACh-mediated effects suggests that SK2 channels play a key role in zebrafish LL HC hyperpolarization, since these channels are the most apamin sensitive (Köhler et al., 1996; Shah and Haylett, 2000; Strøbaek et al., 2000; Stocker, 2004).

Zebrafish neuromasts contain two populations of HCs that are activated by deflections in either the anterior or posterior direction (Flock and Wersall, 1962; Ghysen and DamblyChaudière, 2007). However, only one efferent fiber contacts all HCs of a single neuromast (Faucherre et al., 2009; Dow et al., 2018). Moreover, during fictive locomotion presynaptic activity across all efferent synapses within a neuromast are synchronously activated (Pichler and Lagnado, 2020). Similarly, in our experiments ACh-mediated effects were observed in HCs regardless of their polarity, and the median magnitude of inhibition in both cases showed no significant difference. However, Pichler and Lagnado (2020) reported that efferent modulation is biased toward HCs activated during forward motion. This discrepancy might rely on the fact that our experiments were performed by perfusing $\mathrm{ACh}$ and not by the stimulation of efferent terminals (Pichler and Lagnado, 2020). Differences in the efficiency of presynaptic $\mathrm{ACh}$ release at efferent terminals and/or in the number 
A
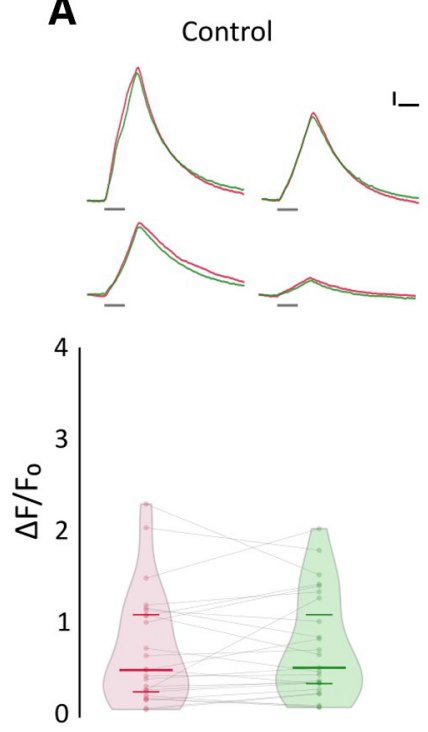

Extra
B
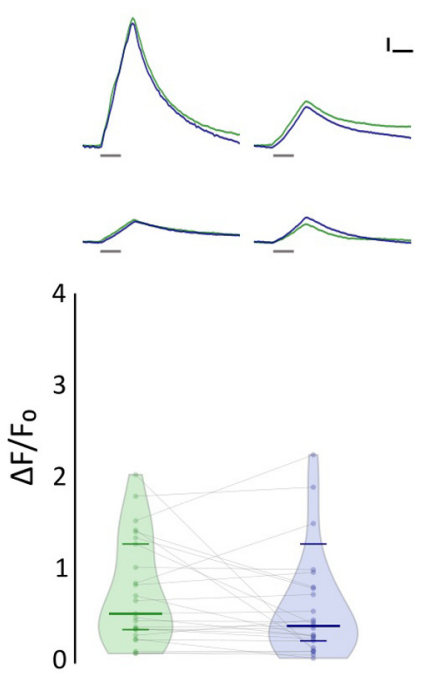

$\alpha-\overline{B t x} \quad \mathrm{ACh}+\alpha-B \operatorname{tx}$
C

Control

D

Apamin
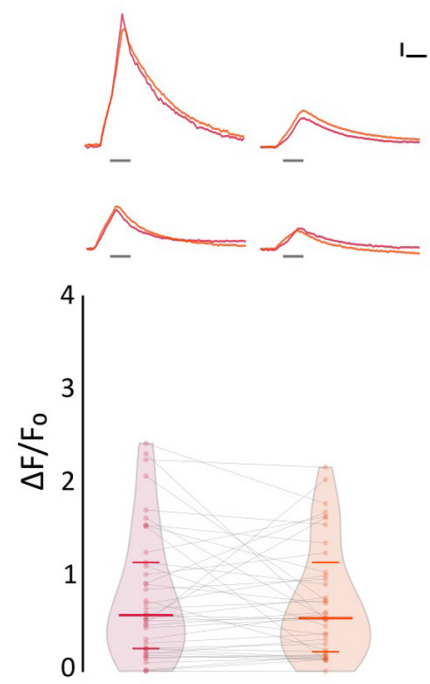

Extra

Apa

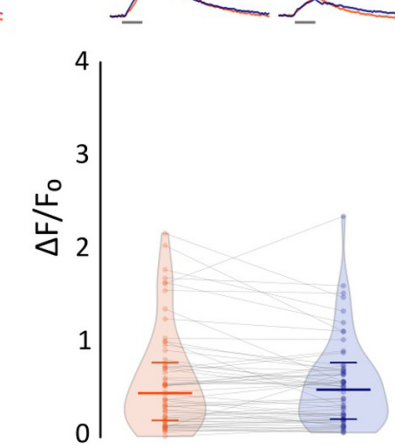

Apa $\quad A C h+A p a$

Figure 7. ACh-mediated inhibition of evoked $\mathrm{Ca}^{2+}$ signals is blocked by $\alpha$-Btx and apamin. $\boldsymbol{A}$, Top, Representative temporal $\Delta F / F_{0}$ curves of mechanosensitive $\mathrm{Ca}^{2+}$ responses of four $\mathrm{HCS}$, before (red) and after (green) the application of $10 \mu \mathrm{m} \alpha$-Btx. Bottom, Mechanosensitive $\mathrm{Ca}^{2+}$ signals show no significant difference before and after $10 \mu \mathrm{m} \alpha$-Btx treatment (Extra: median $\Delta F / F_{0}=0.509 ;$ IQR, $0.252-1.134 ;$ vs $\alpha$-Btx: median $\Delta F / F_{0}=0.534 ;$ IQR, $0.331-1.325 ; n=25, W=-45, p=0.5449, \mathrm{MPRBC}=0.138$ ). $B$, Top, Representative temporal $\Delta F / F_{0}$ curves of mechanosensitive $\mathrm{Ca}^{2+}$ responses of four $\mathrm{HCs}$, after the application of $10 \mu \mathrm{m} \alpha$-Btx (green) and after the coapplication of $1 \mathrm{~mm}$ ACh and $10 \mu \mathrm{m} \alpha$-Btx (blue). Bottom, When coapplied with $10 \mu \mathrm{m} \alpha$-Btx, ACh-mediated inhibition is blocked $(n=25, W=-87, p=0.2521, \mathrm{MPRBC}=0.268)$. C, Top, Representative temporal $\Delta F / F_{0}$ curves of mechanosensitive $\mathrm{C}^{2+}{ }^{2+}$ responses of four hair cells, before (red) and after (orange) the application of $10 \mu \mathrm{m}$ apamin. Bottom, Mechanosensitive $\mathrm{Ca}^{2+}$ signals show no significant difference before and after $10 \mu \mathrm{m}$ apamin treatment (Extra: median $\Delta F / F_{0}=0.599 ;$ IQR, 0.243-1.216; versus Apa: median $\Delta F / F_{0}=0.567 ;$ IQR, 0.191-1.040; $n=41, W=-91, p=0.5554$, MPRBC $=0.106$ ). $D$, Top, Representative temporal $\Delta F / F_{0}$ curves of mechanosensitive $\mathrm{Ca}^{2+}$ responses of four $\mathrm{HCS}$, after the application of $10 \mu \mathrm{m}$ apamin (orange) and after the coapplication of $1 \mathrm{~mm}$ ACh and $10 \mu \mathrm{m}$ apamin (blue). Bottom, ACh-mediated inhibition is blocked by $10 \mu \mathrm{m}$ apamin $(n=60, W=-322, p=0.2359, \mathrm{MPRBC}=0.1759)$. A Wilcoxon matched-pairs signed-rank test was used in all cases. Calibration: $\mathbf{A}-\mathbf{D}$, $1.5 \mathrm{~s} ; \boldsymbol{A}-\boldsymbol{D}, 25 \% \Delta F / F_{0}$. Curves in $\boldsymbol{A}-\boldsymbol{D}$ are aligned to the onset of the mechanical stimulus. The duration of the stimulus is indicated by gray lines below each trace.

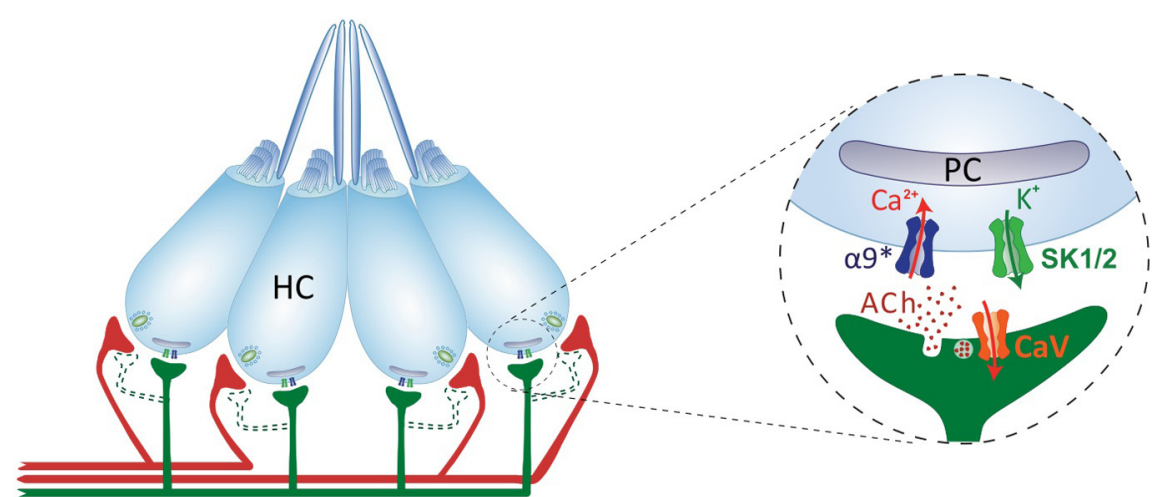

Figure 8. Schematics of the cholinergic LL efferent synapse. LL HCs are innervated by afferent (red) and cholinergic efferent (green) fibers. Evidence for efferent cholinergic fibers contacting afferent neurons (dashed light green) is still missing. The net effect of LL efferent cholinergic activity is to hyperpolarize HCs. This is mediated by the activation of an $\alpha 9 * \mathrm{nAChR}$ with high $\mathrm{Ca}^{2+}$ permeability. Subsequent activation of $\mathrm{Ca}^{2+}$-dependent potassium SK channels drives HC hyperpolarization. Postsynaptic cisterns (PCs) opposed to efferent terminals (Dow et al., 2018) have been proposed to participate in $\mathrm{Ca}^{2+}$ compartmentalization and/or $\mathrm{Ca}^{2+}$-induced $\mathrm{Ca}^{2+}$ release mechanisms.

of efferent terminals per HCs of different polarities might account for this biased efferent modulation. Alternatively, physiological heterogeneity of LL HCs could contribute to differences in the efficiency with which depolarization triggers glutamate release.

HCs within the same neuromast exhibit functional heterogeneity. Stimuli able to open mechanosensitive channels are insufficient to evoke vesicle fusion in the majority of HCs (Zhang et al., 2018). Moreover, synaptically active HCs exhibit lower intracellular $\mathrm{K}^{+}$(Kin) levels than silent HCs. We show that resting
$\mathrm{Ca}^{2+}$ levels are heterogenous too, as reported by Wong et al. (2019). This variability could arise from differences in the expression level of GCaMP7 or from heterogeneity among HCs. Hair cells with lower Kin might be at sufficiently depolarized resting membrane potentials to activate $\mathrm{Ca}_{\mathrm{v}} 1.3$ channels following spontaneous opening of mechanotransduction channels, resulting in higher resting $\mathrm{Ca}^{2+}$ levels. In contrast, HCs with higher Kin levels would exhibit lower resting $\mathrm{Ca}^{2+}$ levels. Furthermore, heterogeneity has also been shown for LL afferent response to efferent activity (Lunsford et al., 2019). In tune with these findings, we show that the ACh-mediated effect on evoked $\mathrm{Ca}^{2+}$ signals is heterogeneous, adding a new level of complexity underlying LL HC function in vivo. Differences in the density of $\alpha 9 * \mathrm{nAChRs}$ and/or SK channels could explain this phenomenon. Alternatively, ACh accessibility to HCs, depending on their location within the neuromast, may also contribute to this variability.

The LL system controls many behaviors such as schooling (Partridge and Pitcher, 1980; Mekdara et al., 2018), prey capture (McHenry et al., 2009; Stewart et al., 2013), and rheotaxis (Bleckmann and Zelick, 2009; Olszewski et al., 2012; Suli et al., 2012; Oteiza et al., 2017). However, the role of the efferent system on the performance of these behaviors remains unknown. Deciphering the molecular players at the zebrafish cholinergic 
LL efferent synapse will enable the generation of molecular tools to selectively manipulate its activity and evaluate its role on sensory processing and associated behaviors in their native context. In addition, because of the overall similarity between mammalian and piscine efferent synapses, zebrafish emerge as an excellent platform to evaluate compounds that target $\alpha 9 *$ nAChRs to treat pathologies such as noise-induced hearing loss and tinnitus.

\section{References}

Arellano RO, Woodward RM, Miledi R (1995) A monovalent cationic conductance that is blocked by extracellular divalent cations in Xenopus oocytes. J Physiol 484:593-604.

Autuori E, Sedlak P, Xu L, C Ridder M, Tedoldi A, Sah P (2019) rSK1 in rat neurons: a controller of membrane rSK2? Front Neural Circuits 13:21.

Ballestero J, Zorrilla de San Martín J, Goutman J, Elgoyhen AB, Fuchs PA, Katz E (2011) Short-term synaptic plasticity regulates the level of olivocochlear inhibition to auditory hair cells. J Neurosci 31:14763-14774.

Barish ME (1983) A transient calcium-dependent chloride current in the immature Xenopus oocyte. J Physiol 342:309-325.

Benton DCH, Monaghan AS, Hosseini R, Bahia PK, Haylett DG, Moss GWJ (2003) Small conductance Ca2+-activated K+ channels formed by the expression of rat SK1 and SK2 genes in HEK 293 cells. J Physiol 553:13-19.

Blanchet C, Eróstegui C, Sugasawa M, Dulon D (1996) Acetylcholineinduced potassium current of guinea pig outer hair cells: its dependence on a calcium influx through nicotinic-like receptors. J Neurosci 16:25742584.

Bleckmann H, Zelick R (2009) Lateral line system of fish. Integr Zool 4:13-25.

Boton R, Dascal N, Gillo B, Lass Y (1989) Two calcium-activated chloride conductances in Xenopus laevis oocytes permeabilized with the ionophore A23187. J Physiol 408:511-534.

Bricaud O, Chaar V, Dambly-Chaudière C, Ghysen A (2001) Early efferent innervation of the zebrafish lateral line: lateral line efference in zebrafish. J Comp Neurol 434:253-261.

Cabo R, Zichichi R, Viña E, Guerrera MC, Vázquez G, García-Suárez O, Vega JA, Germanà A (2013) Calcium-activated potassium channel SK1 is widely expressed in the peripheral nervous system and sensory organs of adult zebrafish. Neurosci Lett 555:62-67.

Corey DP, Hudspeth AJ (1979) Response latency of vertebrate hair cells. Biophys J 26:499-506.

Dawkins R, Keller SL, Sewell WF (2005) Pharmacology of acetylcholinemediated cell signaling in the lateral line organ following efferent stimulation. J Neurophysiol 93:2541-2551.

Doi T, Ohmori H (1993) Acetylcholine increases intracellular Ca2+ concentration and hyperpolarizes the guinea-pig outer hair cell. Hear Res 67:179-188.

Dow E, Jacobo A, Hossain S, Siletti K, Hudspeth AJ (2018) Connectomics of the zebrafish's lateral-line neuromast reveals wiring and miswiring in a simple microcircuit. eLife 7:e33988.

Dulon D, Luo L, Zhang C, Ryan AF (1998) Expression of small-conductance calcium-activated potassium channels (SK) in outer hair cells of the rat cochlea. Eur J Neurosci 10:907-915.

Ebihara L (1996) Xenopus connexin38 forms hemi-gap-junctional channels in the nonjunctional plasma membrane of Xenopus oocytes. Biophys J 71:742-748.

Elgoyhen AB, Katz E (2012) The efferent medial olivocochlear-hair cell synapse. J Physiol Paris 106:47-56.

Elgoyhen AB, Johnson DS, Boulter J, Vetter DE, Heinemann S (1994) $\alpha$ : an acetylcholine receptor with novel pharmacological properties expressed in rat cochlear hair cells. Cell 79:705-715.

Elgoyhen AB, Vetter DE, Katz E, Rothlin CV, Heinemann SF, Boulter J (2001) $\alpha 10$ : a determinant of nicotinic cholinergic receptor function in mammalian vestibular and cochlear mechanosensory hair cells. Proc Natl Acad Sci U S A 98:3501-3506.

Ellis LD, Maler L, Dunn RJ (2008) Differential distribution of SK channel subtypes in the brain of the weakly electric fish Apteronotus leptorhynchus. J Comp Neurol 507:1964-1978.

Erickson T, Nicolson T (2015) Identification of sensory hair-cell transcripts by thiouracil-tagging in zebrafish. BMC Genomics 16:842.
Faucherre A, Pujol-Martí J, Kawakami K, López-Schier H (2009) Afferent neurons of the zebrafish lateral line are strict selectors of hair-cell orientation. PLoS One 4:e4477.

Fettiplace R (2009) Defining features of the hair cell mechanoelectrical transducer channel. Pflugers Arch 458:1115-1123.

Flock A, Russell IJ (1973) The post-synaptic action of efferent fibres in the lateral line organ of the burbot Lota lota. J Physiol 235:591-605.

Flock A, Russell I (1976) Inhibition by efferent nerve fibres: action on hair cells and afferent synaptic transmission in the lateral line canal organ of the burbot Lota lota. J Physiol 257:45-62.

Flock A, Wersall J (1962) A study of the orientation of the sensory hairs of the receptor cells in the lateral line organ of fish, with special reference to the function of the receptors. J Cell Biol 15:19-27.

Franchini LF, Elgoyhen AB (2006) Adaptive evolution in mammalian proteins involved in cochlear outer hair cell electromotility. Mol Phylogenet Evol 41:622-635.

Fuchs PA (2014) A "calcium capacitor" shapes cholinergic inhibition of cochlear hair cells. J Physiol 592:3393-3401.

Gerzanich V, Anand R, Lindstrom J (1994) Homomers of alpha 8 and alpha 7 subunits of nicotinic receptors exhibit similar channel but contrasting binding site properties. Mol Pharmacol 45:212-220.

Ghysen A, Dambly-Chaudière C (2007) The lateral line microcosmos. Genes Dev 21:2118-2130.

Glowatzki E, Fuchs PA (2000) Cholinergic synaptic inhibition of inner hair cells in the neonatal mammalian cochlea. Science 288:2366-2368.

Gómez-Casati ME, Fuchs PA, Elgoyhen AB, Katz E (2005) Biophysical and pharmacological characterization of nicotinic cholinergic receptors in rat cochlear inner hair cells. J Physiol 566:103-118.

Guinan JJ, Stankovic KM (1996) Medial efferent inhibition produces the largest equivalent attenuations at moderate to high sound levels in cat auditory-nerve fibers. J Acoust Soc Am 100:1680-1690.

Hashimoto T, Katsuki Y, Yanagisawa K (1970) Efferent system of lateral-line organ of fish. Comp Biochem Physiol 33:405-421.

Hiel H, Luebke AE, Fuchs PA (2000) Cloning and expression of the alpha9 nicotinic acetylcholine receptor subunit in cochlear hair cells of the chick. Brain Res 858:215-225.

Holt JC, Lioudyno M, Guth PS (2003) A pharmacologically distinct nicotinic ACh receptor is found in a subset of frog semicircular canal hair cells. J Neurophysiol 90:1526-1536.

Hunter JD (2007) Matplotlib: a 2D graphics environment. Comput Sci Eng 9:90-95.

Katz E, Verbitsky M, Rothlin CV, Vetter DE, Heinemann SF, Elgoyhen AB (2000) High calcium permeability and calcium block of the K9 nicotinic acetylcholine receptor. Hear Res 141:117-128.

Katz E, Elgoyhen AB, Gómez-Casati ME, Knipper M, Vetter DE, Fuchs PA, Glowatzki E (2004) Developmental regulation of nicotinic synapses on cochlear inner hair cells. J Neurosci 24:7814-7820.

Kerby DS (2014) The simple difference formula: an approach to teaching nonparametric correlation. Compr Psychol 3:1.

Köhler M, Hirschberg B, Bond CT, Kinzie JM, Marrion NV, Maylie J, Adelman JP (1996) Small-conductance, calcium-activated potassium channels from mammalian brain. Science 273:1709-1714.

Liao JC (2010) Organization and physiology of posterior lateral line afferent neurons in larval zebrafish. Biol Lett 6:402-405.

Liman ER, Tytgat J, Hess P (1992) Subunit stoichiometry of a mammalian $\mathrm{K}^{+}$ channel determined by construction of multimeric cDNAs. Neuron 9:861-871.

Lioudyno M, Hiel H, Kong J-H, Katz E, Waldman E, Parameshwaran-Iyer S, Glowatzki E, Fuchs PA (2004) A "synaptoplasmic cistern" mediates rapid inhibition of cochlear hair cells. J Neurosci 24:11160-11164.

Lipovsek M, Im GJ, Franchini LF, Pisciottano F, Katz E, Fuchs PA, Elgoyhen AB (2012) Phylogenetic differences in calcium permeability of the auditory hair cell cholinergic nicotinic receptor. Proc Natl Acad Sci U S A 109:4308-4313.

Lipovsek M, Fierro A, Pérez EG, Boffi JC, Millar NS, Fuchs PA, Katz E, Elgoyhen AB (2014) Tracking the molecular evolution of calcium permeability in a nicotinic acetylcholine receptor. Mol Biol Evol 31:3250-3265.

Lunsford ET, Skandalis DA, Liao JC (2019) Efferent modulation of spontaneous lateral line activity during and after zebrafish motor commands. J Neurophysiol 122:2438-2448.

Lush ME, Diaz DC, Koenecke N, Baek S, Boldt H, St Peter MK, GaitanEscudero T, Romero-Carvajal A, Busch-Nentwich EM, Perera AG, Hall 
KE, Peak A, Haug JS, Piotrowski T (2019) scRNA-Seq reveals distinct stem cell populations that drive hair cell regeneration after loss of Fgf and Notch signaling. eLife 8:e44431.

Lustig LR, Peng H, Hiel H, Yamamoto T, Fuchs PA (2001) Molecular cloning and mapping of the human nicotinic acetylcholine receptor alpha10 (CHRNA10). Genomics 73:272-283.

Marcovich I, Moglie MJ, Carpaneto Freixas AE, Trigila AP, Franchini LF, Plazas PV, Lipovsek M, Elgoyhen AB (2020) Distinct evolutionary trajectories of neuronal and hair cell nicotinic acetylcholine receptors. Mol Biol Evol 37:1070-1089.

Matern MS, Beirl A, Ogawa Y, Song Y, Paladugu N, Kindt KS, Hertzano R (2018) Transcriptomic profiling of zebrafish hair cells using RiboTag. Front Cell Dev Biol 6:47.

Matthews TM, Duncan RK, Zidanic M, Michael TH, Fuchs PA (2005) Cloning and characterization of SK2 channel from chicken short hair cells. J Comp Physiol A Neuroethol Sens Neural Behav Physiol 191:491-503.

McHenry MJ, Feitl KE, Strother JA, Van Trump WJ (2009) Larval zebrafish rapidly sense the water flow of a predator's strike. Biol Lett 5:477-479.

Mckinney W (2010) Data structures for statistical computing in Python. Paper presented at the 9th Python in Science Conference, Austin, TX, June.

Mekdara PJ, Schwalbe MAB, Coughlin LL, Tytell ED (2018) The effects of lateral line ablation and regeneration in schooling giant danios. J Exp Biol 221:jeb175166.

Metcalfe WK (1989) Organization and development of the zebrafish posterior lateral line. In: The mechanosensory lateral line (Coombs S, Görner P, Münz H, eds), pp 147-159. New York: Springer.

Metcalfe WK, Kimmel CB, Schabtach E (1985) Anatomy of the posterior lateral line system in young larvae of the zebrafish. J Comp Neurol 233:377-389.

Miledi R, Parker I (1984) Chloride current induced by injection of calcium into Xenopus oocytes. J Physiol 357:173-183.

Moglie MJ, Fuchs PA, Elgoyhen AB, Goutman JD (2018) Compartmentalization of antagonistic $\mathrm{Ca} 2+$ signals in developing cochlear hair cells. Proc Natl Acad Sci U S A 115:E2095-E2104.

Moser T, Beutner D (2000) Kinetics of exocytosis and endocytosis at the cochlear inner hair cell afferent synapse of the mouse. Proc Natl Acad Sci U S A 97:883-888.

Muto A, Ohkura M, Abe G, Nakai J, Kawakami K (2013) Real-time visualization of neuronal activity during perception. Curr Biol 23:307-311.

Nenov AP, Norris C, Bobbin RP (1996) Acetylcholine response in guinea pig outer hair cells. II. Activation of a small conductance $\mathrm{Ca}(2+)$-activated K+ channel. Hear Res 101:149-172.

Nicolson T (2005) The genetics of hearing and balance in zebrafish. Annu Rev Genet 39:9-22.

Oliver D, Klöcker N, Schuck J, Baukrowitz T, Ruppersberg JP, Fakler B (2000) Gating of Ca2+-activated $\mathrm{K}+$ channels controls fast inhibitory synaptic transmission at auditory outer hair cells. Neuron 26:595-601.

Olszewski J, Haehnel M, Taguchi M, Liao JC (2012) Zebrafish larvae exhibit rheotaxis and can escape a continuous suction source using their lateral line. PLoS One 7:e36661.

Oteiza P, Odstrcil I, Lauder G, Portugues R, Engert F (2017) A novel mechanism for mechanosensory-based rheotaxis in larval zebrafish. Nature 547:445-448.

Parks XX, Contini D, Jordan PM, Holt JC (2017) Confirming a role for $\alpha 9 \mathrm{nAChRs}$ and SK potassium channels in type II hair cells of the turtle posterior crista. Front Cell Neurosci 11:356.

Partridge BL, Pitcher TJ (1980) The sensory basis of fish schools: relative roles of lateral line and vision. J Comp Physiol 135:315-325.

Perez F, Granger BE (2007) IPython: a system for interactive scientific computing. Comput Sci Eng 9:21-29.

Pichler P, Lagnado L (2020) Motor behavior selectively inhibits hair cells activated by forward motion in the lateral line of zebrafish. Curr Biol 30:150157.e3.

Quick MW, Lester RAJ (2002) Desensitization of neuronal nicotinic receptors. J Neurobiol 53:457-478.

Roberts BL, Russell IJ (1972) The activity of lateral-line efferent neurones in stationary and swimming dogfish. J Exp Biol 57:435-448.

Rueden CT, Schindelin J, Hiner MC, DeZonia BE, Walter AE, Arena ET, Eliceiri KW (2017) ImageJ2: ImageJ for the next generation of scientific image data. BMC Bioinformatics 18:529.
Russell IJ (1971) The role of the lateral-line efferent system in Xenopus laevis. J Exp Biol 54:621-641.

Sailer CA, Kaufmann WA, Marksteiner J, Knaus H-G (2004) Comparative immunohistochemical distribution of three small-conductance Ca2+activated potassium channel subunits, SK1, SK2, and SK3 in mouse brain. Mol Cell Neurosci 26:458-469.

Schindelin J, Arganda-Carreras I, Frise E, Kaynig V, Longair M, Pietzsch T, Preibisch S, Rueden C, Saalfeld S, Schmid B, Tinevez J-Y, White DJ, Hartenstein V, Eliceiri K, Tomancak P, Cardona A (2012) Fiji: an opensource platform for biological-image analysis. Nat Methods 9:676-682.

Sgard F, Charpantier E, Bertrand S, Walker N, Caput D, Graham D, Bertrand D, Besnard F (2002) A novel human nicotinic receptor subunit, alpha10, that confers functionality to the alpha9-subunit. Mol Pharmacol 61:150-159.

Shah M, Haylett DG (2000) The pharmacology of hSK1 Ca2+-activated $\mathrm{K}+$ channels expressed in mammalian cell lines. $\mathrm{Br} \mathrm{J}$ Pharmacol 129:627-630.

Sheets L, Kindt KS, Nicolson T (2012) Presynaptic $\mathrm{Ca}_{V} 1.3$ channels regulate synaptic ribbon size and are required for synaptic maintenance in sensory hair cells. J Neurosci 32:17273-17286.

Sheets L, He XJ, Olt J, Schreck M, Petralia RS, Wang Y-X, Zhang Q, Beirl A, Nicolson T, Marcotti W, Trapani JG, Kindt KS (2017) Enlargement of ribbons in zebrafish hair cells increases calcium currents but disrupts afferent spontaneous activity and timing of stimulus onset. J Neurosci 37:6299-6313.

Steiner AB, Kim T, Cabot V, Hudspeth AJ (2014) Dynamic gene expression by putative hair-cell progenitors during regeneration in the zebrafish lateral line. Proc Natl Acad Sci U S A 111:E1393-E1401.

Stewart WJ, Cardenas GS, McHenry MJ (2013) Zebrafish larvae evade predators by sensing water flow. J Exp Biol 216:388-398.

Stocker M (2004) $\mathrm{Ca}^{2+}$-activated $\mathrm{K}^{+}$channels: molecular determinants and function of the SK family. Nat Rev Neurosci 5:758-770.

Stocker M, Pedarzani P (2000) Differential distribution of three Ca(2+)-activated $\mathrm{K}(+)$ channel subunits, SK1, SK2, and SK3, in the adult rat central nervous system. Mol Cell Neurosci 15:476-493.

Strøbaek D, Jørgensen TD, Christophersen P, Ahring PK, Olesen SP (2000) Pharmacological characterization of small-conductance $\mathrm{Ca}(2+)$-activated $\mathrm{K}(+)$ channels stably expressed in HEK 293 cells. Br J Pharmacol 129:991-999.

Suli A, Watson GM, Rubel EW, Raible DW (2012) Rheotaxis in larval zebrafish is mediated by lateral line mechanosensory hair cells. PLoS One 7: e29727.

Thévenaz P, Ruttimann UE, Unser M (1998) A pyramid approach to subpixel registration based on intensity. IEEE Trans Image Process 7:27-41.

Thisse C, Thisse B (2008) High-resolution in situ hybridization to wholemount zebrafish embryos. Nat Protoc 3:59-69.

Toro C, Trapani JG, Pacentine I, Maeda R, Sheets L, Mo W, Nicolson T (2015) Dopamine modulates the activity of sensory hair cells. J Neurosci 35:16494-16503.

Trapani JG, Nicolson T (2010) Chapter 8-physiological recordings from zebrafish lateral-line hair cells and afferent neurons. Methods Cell Biol 100:219-231.

Trapani JG, Nicolson T (2011) Mechanism of spontaneous activity in afferent neurons of the zebrafish lateral-line organ. J Neurosci 31:1614-1623.

Tricas TC, Highstein SM (1991) Action of the octavolateralis efferent system upon the lateral line of free-swimming toadfish, Opsanus tau. J Comp Physiol A Neuroethol Sens Neural Behav Physiol 169:25-37.

Vetter DE, Katz E, Maison SF, Taranda J, Turcan S, Ballestero J, Liberman MC, Elgoyhen AB, Boulter J (2007) The alpha10 nicotinic acetylcholine receptor subunit is required for normal synaptic function and integrity of the olivocochlear system. Proc Natl Acad Sci U S A 104:20594-20599.

Virtanen P, Gommers R, Oliphant TE, Haberland M, Reddy T, Cournapeau D, Burovski E, Peterson P, Weckesser W, Bright J, van der Walt SJ, Brett M, Wilson J, Millman KJ, Mayorov N, Nelson ARJ, Jones E, Kern R, Larson E, Carey CJ, et al (2020) SciPy 1.0: fundamental algorithms for scientific computing in Python. Nat Methods 17:261-272.

Walt SVD, Colbert SC, Varoquaux G (2011) The NumPy Array: a structure for efficient numerical computation. Comput Sci Eng 13:22-30.

Weisstaub N, Vetter DE, Belén Elgoyhen A, Katz E (2002) The $\alpha 9 \alpha 10$ nicotinic acetylcholine receptor is permeable to and is modulated by divalent cations. Hear Res 167:122-135. 
Westerfield M (2000) The zebrafish book. A guide for the laboratory use of zebrafish (Danio rerio). 4th ed., Univ. of Oregon Press, Eugene.

Wong H-TC, Zhang Q, Beirl AJ, Petralia RS, Wang Y-X, Kindt K (2019) Synaptic mitochondria regulate hair-cell synapse size and function. Elife 8:

Xiao T, Baier H (2007) Lamina-specific axonal projections in the zebrafish tectum require the type IV collagen dragnet. Nat Neurosci 10: 1529-1537.

Yamamoto T, Kakehata S, Yamada T, Saito T, Saito H, Akaike N (1997) Effects of potassium channel blockers on the acetylcholine-induced currents in dissociated outer hair cells of guinea pig cochlea. Neurosci Lett 236:79-82.
Yuhas WA, Fuchs PA (1999) Apamin-sensitive, small-conductance, calciumactivated potassium channels mediate cholinergic inhibition of chick auditory hair cells. J Comp Physiol A Neuroethol Sens Neural Behav Physiol 185:455-462.

Zachary S, Nowak N, Vyas P, Bonanni L, Fuchs PA (2018) Voltage-gated calcium influx modifies cholinergic inhibition of inner hair cells in the immature rat cochlea. J Neurosci 38:5677-5687.

Zhang Q, Li S, Wong H-TC, He XJ, Beirl A, Petralia RS, Wang Y-X, Kindt KS (2018) Synaptically silent sensory hair cells in zebrafish are recruited after damage. Nat Commun 9:1388.

Zottoli SJ, Van Horne C (1983) Posterior lateral line afferent and efferent pathways within the central nervous system of the goldfish with special reference to the Mauthner cell. J Comp Neurol 219:100-111. 